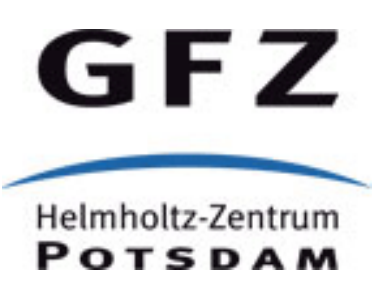

Originally published as:

Yoon, J., Zang, A., Stephansson, O. (2012): Simulating fracture and friction of Aue granite under confined asymmetric compressive test using clumped particle model. - International Journal of Rock Mechanics and Mining Sciences, 49, 68-83

DOI: 10.1016/j.ijrmms.2011.11.004 


\title{
Simulating fracture and friction of Aue granite under confined asymmetric compressive test using clumped particle model
}

\author{
Jeoung Seok YOON*, Arno ZANG and Ove STEPHANSSON
}

\section{Jeoung Seok YOON ${ }^{1}$ (*Corresponding Author)}

Affiliation: Centre for Energy Research of Lower Saxony (EFZN), Goslar, Germany

Contact : Email: jeoungseok.yoon@efzn.de

Tel: +49-5321-3816-8111, Fax: +49-5321-3816-8196

\section{Arno ZANG}

Affiliation: GFZ German Research Centre for Geosciences, Section 2.6 Seismic Hazard and Stress Field, Potsdam, Germany

Contact: E-mail: zang@gfz-potsdam.de

Tel: +49-331-288-1325, Fax: +49-331-288-1127

\section{Ove STEPHANSSON}

Affiliation: GFZ German Research Centre for Geosciences, Section 2.6 Seismic Hazard and Stress Field, Potsdam, Germany

Contact: E-mail: ove@stephansson.de

Tel: +49-331-288-1908, Fax: +49-331-288-1127

\footnotetext{
${ }^{1}$ Currently affiliated to geomecon $\mathrm{GmbH}$

Address: August-Bebel-Str. 27, 14482 Potsdam, Germany

Contact : E-mail: jeoungseok.yoon@geomecon.de

Tel: +49-331-9799-6868; Fax: +49-331-9799-6867
} 


\section{Abstract}

Fracture and friction behaviors of Aue granite (Erzgebirge, Germany) under confined asymmetric load are simulated by using the discrete element method. Clumped particle model is designed to account for stress heterogeneities under compressive load in the rock microstructure which affect both, fracture and friction properties. In contrast to conventional circular bonded particle assembly, clumped particle models consist of groups of neighboring individual particles tied together to mimic unbreakable larger grains of irregular shape (clumps). An optimized clumped model is used for all calculations which is calibrated by the strength and deformation data from uniaxial and triaxial compression of Aue granite determined in the laboratory. At first order approximation, the simulated fracture paths obtained from the clumped particle model match the observed fracture paths from laboratory experiments at various confinements. Under low confinement $(<5 \mathrm{MPa})$, the fracture initiates in mode I from the edge of the asymmetric loading platen and propagates toward the unloaded portion of the granite. In this scenario, tensile cracks dominate in the fracture process zone. Under higher confining pressures (10 and $40 \mathrm{MPa}$ ), after nucleus of mode I fracture an inclined rupture path develops and propagates towards the loaded portion of model. A close view on such rupture path indicates that it is a mixture of vertically aligned isolated tensile cracks in echelon pattern and inclined shear cracks connecting those tensile cracks. Temporal change of the numerically computed GutenbergRichter $b$-values shows low $b$-values in the fracturing regime and higher $b$-values during stickslip and frictional sliding post-failure regime, which are in accordance with laboratory findings.

\section{Keywords}

Clumped Particle Model (CPM), Confined Asymmetric Test (CAT), Discrete Element Method (DEM), Fracture Propagation Path, Friction Behavior of Rock, Gutenberg-Richter $b$-value 


\section{Introduction}

Most earthquakes occur on pre-existing faults [1]; sometimes the formation of new faults in intact rock mass is also observed [2]. Physically, the earthquake is a frictional sliding phenomenon in the former and a fracture phenomenon in the latter case. At laboratory scale, the two phenomena can be investigated in terms of acoustic emissions which have different signatures for fracture-related events [3] and friction-related stick-slip events [4]. Several triaxial rock test configurations have been used to investigate rock fracture [5-9] and rock friction properties [10-16]. Only few studies, however, were designed to examine both types of source mechanisms in one test configuration [17-19]. In [18], a confined asymmetric test (CAT) configuration was used first, to pre-determine the fracture nucleus at top of the granite core and second, to control the speed of single rupture formed by the rate of acoustic emissions [20]. The observed fracture path for different confining pressures, however, is still difficult to predict by numerical tools [21]. This in part is due to the simultaneous contribution of fracture (e.g. strength) and friction properties (e.g. friction coefficient) to the final rupture path formation in rock.

This paper focuses on reproducing the fracture propagation path in Aue granite (Erzgebirge, Germany) stressed to failure in the laboratory at zero, 10 and $40 \mathrm{MPa}$ confining pressures by bonded particle model simulation [22] which is based on the discrete element method [23]. In previous studies physical material models are represented by assemblies of circular particles bonded at their contact points and simulated for various engineering applications [24-34]. In this study, a particle clumping algorithm is applied [35-37] which accounts for more realistic distributions of stress heterogeneities in the microstructure of the granite under compressive load. In the fracture process zone, also source mechanisms of cracks are determined and crack orientation and magnitude statistics is analyzed. Results are discussed 
in terms of earthquake prediction precursors, where temporal variation of Gutenberg-Richter $b$ values in different types of deformation simulated in clumped particle model is compared to that of laboratory tested rocks. 


\section{Confined Asymmetric Test - experimental and numerical setup}

Fig.1a shows the setup of the confined asymmetric test (CAT) assembly with AE sensors glued directly to the sample surface for monitoring acoustic emission waveforms. Holes in the rubber tube were sealed using two-component epoxy. Fracture propagation during CAT is shown schematically in two dimensions (Fig.1b), and for reference, laboratory tested deformed core is shown with loading configuration (Fig.1c). In CAT, the shear rupture is forced to nucleate at the top of the core near the asymmetric loading platen (Fig.1b, solid line with shear symbol) and propagates downwards into the intact rock material by generating crack events ahead of the shear rupture tip, the so-called fracture process zone (Fig.1b, short bars). In CAT, the stress concentration at top of the core is caused by the contrast in the modulus of the steel plate covering $80 \%$ of the loading area (Fig.1c, yellow arrows on top) and a teflon fill-in covering $20 \%$ of the top loading area (Fig. $1 \mathrm{c}$, blue color). Compared to conventional triaxial testing where the rupture nucleus is determined by sample heterogeneities, the rupture nucleus in CAT is always fixed on top of the core.

In CAT, axial loading on the core specimen can be displacement controlled (fixed displacement rate controlled test) or servo-controlled based on the acoustic emission event rate (AE rate controlled test) recorded by one sensor located close to the rupture nucleus (Fig.1b, sensor 7). For acoustic emission rates below the trigger level of the control sensor, a fixed displacement rate loading $(0.02 \mathrm{~mm} / \mathrm{min})$ was applied; for rates above the trigger level, the axial load was applied at $10^{-10} \mathrm{~mm} / \mathrm{min}$ loading. In this sense, the trigger level of the rate control sensor enabled the speed of the acoustic process zone in front of the fracture tip to be varied by three orders of magnitude, i.e. from the range of $\mathrm{mm} / \mathrm{sec}$ in fixed displacement rate control to $\mu \mathrm{m} / \mathrm{sec}$ in acoustic emission rate control tests [18]. By adapting the threshold level of the control sensor, this testing procedure allows to extend the fracture propagation regime in rock into 
several stages generating an equivalent number of events for both, the fracture and frictional sliding regime of rock tested.

The simplified 2D numerical setup for simulations of CAT on clumped particle model is shown in Fig.1d. Boundary conditions include the length of the top loading wall which is shortened to $30 \mathrm{~mm}$ (core diameter $50 \mathrm{~mm}$ ), leaving the upper left portion of the model free of load. Loading by top and bottom walls is applied in constant displacement rate $(0.05 \mathrm{~m} / \mathrm{sec})$ condition, while the velocities of two lateral walls are servo-controlled to maintain a pre-defined confining pressure throughout the simulation. Also, models are run dynamically with low damping which is intended to measure seismicity, e.g. seismic moment, magnitude, and to calculate Gutenberg-Richter $b$-values. One monitoring circle (Fig.1d, red circle) is inserted in the CPM to keep track of the stress components $\left(\sigma_{x}, \sigma_{y}, \sigma_{x y}\right)$ evolving locally within the encircled area. This allows following principal stresses change as crack accumulates and shear rupture develops in the model. The stress monitoring circle is placed where the fracture propagation path is expected to change quickly over short distances (e.g. kinking). 


\section{Tested rock and clumped particle model}

The geologic characteristics of the different types of granites from the West Erzgebirge are described in [38]. The mechanical properties of the tested red Aue granite from Blauenthal, Germany (red syeno-monzo granite) are summarized in Table 1. Properties including fracture toughness of Aue granite determined experimentally are presented in left column of Table 1. Average uniaxial compressive strength (UCS) of the rock is $134 \mathrm{MPa}$, Young's modulus $48 \mathrm{GPa}$ and Poisson's ratio 0.19. Peak friction angle and cohesion obtained from triaxial compression tests are $52^{\circ}$ and $23 \mathrm{MPa}$, respectively. Mode I and Mode II fracture toughnesses $\left(K_{I C}, K_{I I C}\right)$ are determined by Chevron Bend method and Punch Through Shear test [39-41], respectively. The ratio of $K_{I I C} / K_{I C}$ varies from 1.4 to 2.6 at atmospheric and to 8.3 at confining pressure higher than $30 \mathrm{MPa}$.

In Bonded Particle Model (BPM) simulations, the physical material tested is represented by an assembly of circular particles bonded at their contacting points with finite strengths against tensile and shear. In BPM simulation, there are two types of bonding model provided which are contact bond model and parallel bond model. Contact bond model is used in this study.

A contact bond can be envisioned as a pair of elastic springs with constant normal $\left(k_{n}\right)$ and shear stiffness $\left(k_{s}\right)$ acting at a contact point (Fig.2). Each spring has a specified tensile strength $\left(\sigma_{c}^{\text {tensile }}\right)$ and shear strength $\left(\tau_{c}^{\text {shear }}\right)$. The force-displacement behavior relating the normal and shear components of contact force and relative displacement for particle contact occurring at a point are used to define bond micro-failure. If the magnitude of the tensile normal contact force equals or exceeds the contact bond tensile strength, the bond breaks, i.e. tensile crack (Fig.1d, black short bars), and both the normal and shear contact forces are set to zero. If the magnitude of the shear contact force equals or exceeds the contact bond shear strength, the bond 
breaks, i.e. shear crack (Fig.1d, red short bars), and the shear contact force is reduced to friction coefficient times normal compressive contact force.

For generation of CPMs, we use the stamping logic [35-37], which literally stamps circles randomly with varying diameters within a bonded particle model (Fig.3a) that is generated using the micro-parameters listed in Table 2. Locations of the stamps are determined by $\mathrm{x}$ - and $\mathrm{y}$-coordinates of stamp centers which are chosen randomly within the model boundary (width: $0.05 \mathrm{~m}$, height: $0.1 \mathrm{~m}$ ). Diameters of the stamps are chosen randomly from an uniform distribution between lower and upper bounds, 0 and $4 \mathrm{~mm}$, therefore giving average diameter of $2 \mathrm{~mm}$. Those particles of which the centers are trapped in the stamp are grouped together as a clump (Fig.3b). Stamping continues until the iteration number reaches total number of particles in the model. Because of random positioning of the stamps, a particle that was previously a member of one clump can be restamped and become a new member of another new clump. Such randomness lets some of the particles be left out, i.e. not belong to any clump. Such individual particles can act as single circular clumps which are analogous to rock grains that have rounded shape and located between bigger angular neighboring grains as can be seen in Fig.3e (indicated by arrows). As a result of stamping and clumping, a CPM is obtained (Fig.3c) of which packing structure (Fig.3d) is supposed to resemble the microstructure of Aue granite (Fig.3e). The quartz content is about $30 \mathrm{vol} \%$, the feldspar content $60 \mathrm{vol} \%$, and mica $10 \mathrm{vol} \%$, respectively [42]. Average grain size of the red Aue granite is $1.35 \mathrm{~mm}$ [42], but grains up to 5 $\mathrm{mm}$ diameter are found [39].

As mentioned earlier, diameters of the circular stamps are chosen randomly from a uniform distribution between 0 and $4 \mathrm{~mm}$, giving average of $2 \mathrm{~mm}$. The size (2D area) of one clump is calculated by summing all the particle area comprising the clump. Although the stamp diameter follows uniform distribution, clump size (2D area) distribution shows rather an 
exponential decay (Fig.4a). As proxy, the exponential decay of the clump size distribution can be used to simulate the actual grain size distribution in Aue granite measured (Fig.4b).

Mechanical properties of the CPM are listed in right column of Table 1 which are averaged values obtained from simulation runs on 10 CPMs that have identical particle contact properties but with different packing structures. Different packing structures were made by changing the seed of random number generator that is used in random positioning of the stamps. Different seed number of random number generator results in different locations of the stamps, therefore results in different packing structures and initial contact force chains.

The properties assigned at particle contacts, e.g. contact stiffness $\left(k_{n}, k_{s}\right)$, bond strength $\left(\sigma_{c}, \tau_{c}\right)$ and at particle, e.g. rigidity of particle $\left(E_{c}\right)$, density $(\rho)$, radius $\left(r_{\min }, r_{\max }\right)$, friction coefficient $(\mu)$ (referred to hereafter as micro-parameters in Table 2), were calibrated so that the macroscopic properties of CPM resemble that of Aue granite. Strength of bonds (tensile/shear) at contacts can be chosen from Gaussian distribution that is defined by means $\left(\sigma_{c, \text { mean }}, \tau_{c, \text { mean }}\right)$ and standard deviations $\left(\sigma_{c, \text { std.dev, }} \tau_{c, \text { std.dev. }}\right)$ of bond strength as in Table 2. Giving non-zero standard deviation could ensure heterogeneity in bond strength distribution. However, in this study, we tried to exclude bond strength heterogeneity by giving zero standard deviations when generating a CPM and to focus on microstructure heterogeneity in optimizing strength, deformation and fracture properties of Aue granite in CAT.

Unlike in conventional particle model calibration where an optimized method is used to determine the micro-parameters [31], calibration was done manually in the present study, which means that all micro-parameters in CPM were changed one at a time and the resulting macroscopic properties were directly compared to the experimental target values. Such process is repeated until the differences fall below a lower bound. For example, the UCS of CPM (Table $1,150 \mathrm{MPa}$ ) is within $10 \%$ of Aue granite UCS (Table 1, $134 \mathrm{MPa}$ ). Analogous bounds are set 
for the remaining mechanical rock parameters.

Young's modulus, Poisson's ratio, peak friction angle and cohesion of CPM are in good agreement with those of Aue granite. Two additional macroscopic properties are checked which are crack-initiation and crack-damage stress levels.

Crack-initiation stress level (Fig.5a, $\sigma_{\mathrm{ci}}$ ) of CPM under uniaxial compression is defined as a point in the stress-strain curve showing deviation from linearity. Since it was hard to detect the point where the slope deviates from linearity, we used axial stiffness curve which is made by differentiating the axial stress curve. From Fig.5a, crack initiation stress $\left(\sigma_{\mathrm{ci}}, 34 \%\right.$ of UCS $)$ is defined where the axial stiffness curve begins to show fluctuation, indicating that $50 \mathrm{GPa}$ axial stiffness (which is Young's modulus) is no longer maintained due to continuous emission of tensile cracks. Crack-damage stress (Fig. $5 \mathrm{a}, \sigma_{\mathrm{cd}}, 82 \%$ of UCS) is defined as the point in the stress-strain curve where the slope of the volumetric strain changes from positive to negative, which indicates start of dilation (Fig.5b). This occurs at 0.0025 axial strain (Fig.5b). Dilation begins at this axial strain which is also indicated by the emission of shear cracks.

Since, crack-initiation $\left(\sigma_{\mathrm{ci}}\right)$ and crack-damage $\left(\sigma_{\mathrm{cd}}\right)$ stress levels of Aue granite are unavailable, two stress levels are taken from the literatures for comparison. Chang and Lee [43] have determined these two stress levels by monitoring volumetric strain changes and acoustic emission hits during uniaxial compression tests on Hwangdeung granite. Eberhardt et al. [44] did the same for the Lac du Bonnet granite. Assuming that the stress levels for crack initiation and crack damage of Aue granite are in the similar range as those found for Hwangdeung and Lac du Bonnet granite: $33-39 \%$ of UCS and $75-89 \%$ of UCS, respectively (Table 1), two stress leels determined in the CPM uniaxial compression simulation are in reasonable ranges.

Residual friction angle $\left(42-51^{\circ}\right)$ was obtained by performing biaxial compression simulation and by continuing loading until clear plateau in stress-strain curve is reached from 
which residual strength and residual friction angle were computed.

Simulated tensile strength of CPM from Brazilian test is higher than that of Aue granite by a factor of 2.5. However, recent modeling effort [37] shows that by having certain number of bonded contacts unbonded after generation of CPM, it is possible to reproduce fair ratio of compressive to tensile strength which is higher than 10. This approach accounts for pre-existing microcracks (unbonded contacts) [45] but is not taken into account in this study. 


\section{Results}

Results of the numerical simulations are presented with emphasis on comparison with the results from laboratory CAT experiments [18], which involve fracture propagation paths at various confining pressures, statistical analysis of crack type sources and temporal variation of amplitude frequency distributions of cracking events.

\subsection{Load vs. time curve at $10 \mathrm{MPa}$ confining pressure}

Using the CPM calibrated for Aue granite properties, we calculated the variation of load and cumulative number of cracks in the CAT loading scenario with $10 \mathrm{MPa}$ confining pressure (Fig.6a). In CPM simulation, we normalized the load curve by the peak load. Computed load (Fig.6a vertical axis) corresponds to the reaction force the upper loading platen received from the CPM. The horizontal axis represents time steps (cumulative number of cycles) normalized to the cumulative cycle number at which the peak load was reached.

For reference, the acoustic emission (assumed to be crack-related) and mechanical data for the laboratory CAT-10 MPa scenario with displacement-rate $(0.02 \mathrm{~mm} / \mathrm{min})$ control are shown in Fig.6b. A first sharp increase in cumulative AE number is observed at $915 \mathrm{sec}$ (also indicated by a small force drop), and is caused by the initiation of mode I crack under the asymmetric loading platen [20]. The maximum number of AE events occur during final shear failure of the core (time $1630 \mathrm{sec}$ ) associated with a force drop of $175 \mathrm{kN}$. Time gaps (40 sec) in the experimental recording of AE are caused by the dead time of the transient recorder (Fig.6b). In CPM simulations (Fig.6a), the load drop caused by mode I rupture nucleus occurs at time 0.82 (failure time $t=1$ ) at about $90 \%$ of the peak load value. In the laboratory CAT (Fig.6b), mode I rupture nucleus occurred at normalized time 0.56 (failure time $1630 \mathrm{sec}$ ) at $70 \%$ of peak load value. In both simulated CPM and laboratory CAT, mode I rupture is accompanied by 
$\sim 1000 \mathrm{AE}$ (cracks). However, $5000 \mathrm{AE}$ are detected during laboratory rock shear failure (Fig.6b) while only 1000 cracks are formed in CPM.

\subsection{Growth of rupture at 10 MPa confining pressure}

Growth of rupture path in $\mathrm{CPM}$ at $10 \mathrm{MPa}$ confining pressure is presented by cumulative crack pattern divided in four stages (Fig.7a-d). In stage 1 (Fig.7a, fracture nucleus), cracks occur below the asymmetric loading platen (stress concentrator) and have mostly tensile source mechanisms (Fig.7a, black short bars). In stage 2 (Fig.7b, vertical fracture propagation) the cluster of cracks extends in the vertical direction to about below the center of the specimen (55 mm). In stage 3 (Fig.7c, kinking of rupture path), the crack cluster changes direction by 30 $40^{\circ}$ (Fig.7c, yellow bars) and starts to grow towards the bottom right corner of the model. In stage 4 (Fig.7d), the CPM starts to dissect (falls apart) by large number of shear cracks forming and connecting tensile fractures that were generated during stages 1-3. Generation of shear cracks connecting tensile cracks produced stick-slip behavior of the CPM which is followed by frictional sliding along the inclined rupture path.

For reference, orientation distribution of crack plane normal for tensile and shear cracks that are generated during stages 1-4 are shown in Fig.7e-h, respectively. Inlet figure in Fig.7e shows definition of orientation of crack plane normal, which is positive when counted anticlockwise from positive $\mathrm{x}$-axis. Cumulative number of tensile and shear cracks and their relative portions at each stage are presented at the top of each histogram. In stages 1 and 2, tensile cracks that are aligned sub-vertically dominate which is shown by grey bar plot (Fig.7e-f, orientation 0 and 180 degrees). Number of tensile cracks increase from 387 (stage 1) to 659 (stage 2). Relative portion of tensile crack in the total crack population in stage 1 and 2 is $86 \%$. In the kinking phase of rupture path (stage 3), relative portion of shear crack increases to $24 \%$, 
whereas that of tensile cracks decreases to $76 \%$ from $86 \%$ (Fig. $7 \mathrm{~g}$ ), which further decreases to $69 \%$ as the inclined rupture path is fully developed (Fig.7h). The orientation distribution of shear crack plane normal is bimodal with two maxima, one near $30^{\circ}$ and the other near $120^{\circ}$. During stages 1 and 2, shear cracks are formed in a way that connects the vertical tensile cracks with certain inclination angles near $30^{\circ}$ and $120^{\circ}$. Vertical tensile cracks are formed in overlapping pattern but isolated to each other (en échelon fractures) near the zone where kinking of rupture path is expected to occur. As more shear cracks appear (stage 4), the isolated tensile fracture are progressively interconnected by the shear crakcs and the rupture path gradually develops. The shear cracks are generated more or less parallel to the inclined rupture path marked by the yellow bar (Fig.7c). This leads to concentration of the shear crack plane normal orientated $30^{\circ}$. As the rupture path is fully developed (stage 4), more shear cracks appear. Overall, relative portion of shear cracks in the total crack population increases from $14 \%$ to $31 \%$ as CPM deforms from stage of vertical fracturing through rupture path kinking till the final rupture reaches the bottom right corner of the model.

The distribution of acoustic emissions (AE) hypocenters (assumed to represent crack locations) detected during CAT-10 MPa on Aue granite with AE rate control are shown in Fig.8. The first three diagrams (Fig.8a-c) correspond to fracture regime while the last one corresponds to frictional sliding regime. In total, $1712(144+410+610+548)$ AE hypocenters were located, $1164(144+410+610)$ during fracture regime and 548 during frictional sliding regime. Analogous to CPM crack pattern, the AE cloud first develops under the asymmetric steel loading platen (Fig.8a, stage 1a) and propagates sub-vertically (Fig.8b, stage 1b), makes a kink (Fig.8c, stage 1c) and undergoes frictional sliding and leaves AE events located mainly in the hanging wall of the sheared specimen (Fig.8d, stage 2). In this sense, CPM crack patterns fit the evolution of the acoustic emission process zone propagating ahead of the shear rupture. 
There are, however, also notable differences. For example, the simulated rupture path runs all the way down to the bottom right corner in CPM simulation (Fig.7c-d) while the observed AE hypocenter cloud arrests $20 \mathrm{~mm}$ above the bottom loading plate (Fig. $8 \mathrm{c}-\mathrm{d}$ ) in case of CAT on Aue granite. Also the 3D pattern of AE in the core seems to be more localized compared to the crack pattern in the 2D CPM simulations, most pronounced in the frictional sliding regime (Fig.8d vs. Fig.7d). This will be addressed in the discussion.

\subsection{Confined rupture paths and crack statistics}

In the laboratory CAT, different fracture paths were observed as the applied confining pressure increases. Fig.9a shows the traces of fractures made visible by impregnation of blueepoxy in thin sections cut from the deformed core halves. The samples were tested at atmospheric, 10, and $40 \mathrm{MPa}$ confining pressures. At atmospheric pressure (Fig.9a-1), the fracture initiated at the point (2D) or edge (3D) of the asymmetric steel loading platen, and propagates sub-vertically towards the non-loaded portion of the core $(3 \mathrm{D})$. The fracture path shows two parallel segments, one of which stops $20 \mathrm{~mm}$ below the loading platen, the other one starts $10 \mathrm{~mm}$ below the loading platen with some offset (Fig.9a-1). Overall rupture path is tilted $10^{\circ}$ from vertical and shows tensile splitting features also at grain scale [8]. At $10 \mathrm{MPa}$ confinement (Fig.9a-2), the fracture nucleating in mode I at the edge of the loading platen propagates towards the loaded portion of the core. Analyzing the damage zone in thin sections, en échelon cracks are found (Fig.3e). The kink in rupture plane visible at $10 \mathrm{MPa}$ confining pressure disappears for higher confining pressures (Fig.9a-3). The width of the fracture process zone narrows with increasing confinement and the fracture ligaments form a more or less straight line. At $40 \mathrm{MPa}$, however, the rupture needs two attempts to nucleate from the CAT plate (Fig.9a-3, bifurcation). In addition, an unloading crack occurs at the lower right corner of 
the specimen where the rupture intersects the core mantle (Fig.9a-3, unloading crack).

The fracture paths simulated in CPM are shown in Fig.9b for the same three levels of confining pressure. At atmospheric confining pressure (Fig.9b-1), the fracture path propagates into non-loaded portion of the model. Increased confining pressure (Fig.9b-2 and 9b-3) causes fractures to propagate into the loaded portion of the model. The fracture path into the nonloaded portion of the model is mainly composed of tensile cracks oriented sub-vertical (Fig.9c1). Fractures propagating into the loaded portion of the model show an increasing number of shear cracks having bimodal orientation distributions (Fig.9c-2 and 9c-3). One maximum occurs near $30^{\circ}$ and one near $130^{\circ}$, most pronounced in the CAT of CPM with $40 \mathrm{MPa}$ confining pressure (Fig.9c-3). Shear cracks are localized along the fracture path which bisects the model from the tip of the asymmetric loading platen to the bottom right corner of the CPM. Higher confining pressure suppresses tensile splitting and results in failure of the model via shear cracks. The percentage of shear cracks increases from $9 \%$ at atmospheric pressure to $24 \%$ at 10 $\mathrm{MPa}$, and reaches $45 \%$ at $40 \mathrm{MPa}$ confining pressure.

\subsection{Temporal variation of $b$-values}

Acoustic emission and seismicity modeling technique developed by Hazzard and Young [46] is adopted in CAT of CPM, in order to investigate how closely Gutenberg-Richter $b$ values simulated in CPM for fracture and frictional sliding regimes resemble the seismic $b$ generally observed and a few experimental observations made on rock cores.

In CPM simulation, it is assumed that each bond breakage represents a single crack in rock. When a bond breaks, the two particles on either side of the crack (bond breakage) will move and contacts surrounding the two source particles will suffer some deformation resulting in changes of contact force at the surrounding contacts. From contact locations and force 
changes, and by integrating those surrounding the crack, components of the $2 \mathrm{D}$ moment tensor are calculated. Moment magnitudes are then calculated from the moment tensor matrix. Details of the technique and its applications to rock test modeling and spalling problems in tunnel excavation can be found in the Hazzard and Young [26,46,47].

Model is run dynamically by specifying appropriate level of numerical damping to simulate realistic level of attenuation or energy loss in rocks, which is generally expressed by dimensionless seismic quality factor $Q$ [48]. The seismic quality factor $Q$ is inversely proportional to attenuation, and is directly related to numerical damping in CPM using equation: $Q=\pi / 2 \alpha$, where $\alpha$ is local damping coefficient used to calculate the damping force applied to each particle [22]. By specifying a damping coefficient, strain energy released from the particle contacts after bond breakage is partially converted into kinetic energy and seismic source information is calculated. For Aue granite CPM, $Q \sim 200$ is assumed, since $Q$ of Lac du Bonnet granite in situ is about 220 [49] and granite generally has $Q$ of 250 [48].

In Fig.10, the cumulative number of cracks vs. moment magnitude is plotted following the Gutenberg-Richter type frequency-magnitude relation [50]. The dashed red line indicates that there are 50 cracks of which the magnitudes are greater than -4.75 . The $b$-value was computed by fitting the linear part of the plotted data. Rao and Prasanna Lakshmi [51] pointed out that $\mathrm{AE}$ amplitude vs. frequency relation does not always exhibit a single straight line but rather show a curved shape. They proposed an improved way of determining $b$-value which involves filtering of high and low amplitude AE hits in a selective manner. In the present study, however, we simply used linear fitting to those data points lying linearly in between magnitude 5.1 and -4.2 , resulting in $b$-value of 2.6.

The computed $b$-values from the magnitude-frequency relations for various points in the load vs. time curve are plotted in Fig.11a. Initial part of the curve (shaded area) corresponds 
to the load vs. time curve presented in Fig.6a. Also, four points are marked along the load curve which correspond to the four snap shots presented in Fig.7 (7a,b: fracturing regime; 7c: stickslip regime; 7d: frictional sliding regime). Fracture initiation and growth in vertical correspond to the first load drop $\left(\mathrm{B}_{1}\right)$. The second load drop $\left(\mathrm{B}_{2}\right)$ is associated with the fracture kinking and fully growth of rupture path that extends to the bottom right corner of the model. Time window covering the two load drops (shaded area) is presented in Fig.6a. Loading was further continued after the load drop $\mathrm{B}_{2}$ to induce sliding of the hanging wall block over the foot wall block. As a result, frictional sliding does not appear right after the fracturing stage, but rather a stick-slip type behavior was observed where kinetic energy released by cracking as well as frictional energy dissipated by sliding are both present. Stick-slip type behavior is followed by purer frictional sliding type which is characterized by gradual increase of dissipated frictional energy and hardly visible kinetic energy release.

Low $b$-values $(<2)$ are calculated for cracks generated during the fracturing regime (Fig.10a, red dots). An increase in $b$-value $(>2.5)$ is observed in the stick-slip regime with further increase in $b$-value ( $>3$ ) in the frictional sliding regime (Fig.10a, blue dots). Qualitatively, such behavior of $b$-values is consistent with experimental findings on oven-dried Darley Dale sandstone at $50 \mathrm{MPa}$ confining pressure [52-54]. Stressed to failure in the laboratory, Darley Dale sandstone is characterized by low $b$-values in the fracturing and high $b$-values in the frictional sliding regime.

Largest magnitude events (Fig.11b, blue dots up to $M=-4$ ) occur before corresponding load drops in the CPM simulations (Fig.11a, $B_{1}-B_{3}$ ). Number of crack events per time interval $(\Delta \mathrm{N} / \Delta \mathrm{t})$ indicate bursts with event rates as high as 400 events per 0.01 normalized time increment (Fig.11b, right ordinate). Cascade like fractures (bursts $B_{1}-B_{3}$ ) are followed by time intervals of quiescence with no cracks (Fig.11b, $\mathrm{Q}_{1}-\mathrm{Q}_{3}$ ), and are restricted to the fracturing and 
stick-slip regime. A characteristic feature of events in the frictional sliding regime is the occurrence of very low magnitude events (Fig.11b, orange and red dots, $M=-7.5$ ) an explanation of which is given in the discussion. 


\section{Discussion}

In this section, possible reasons for inconsistency between the results from CPM simulation and laboratory CAT results are discussed. In Fig.6a, where normalized load and number of cracks are plotted with respect to normalized time for CPM, the first load drop where mode I fracture develops appears at $90 \%$ of peak load, whereas in laboratory CAT the first load drop appears at $70 \%$ of peak load. Such discrepancy may have resultede from (1) different loading rate, and (2) size and strength differences between clumps and rock grain distributions.

In faster loading rate in laboratory experiments, it is observed that rock specimens often exhibit higher failure strength with high degree of damaging, whereas in slower loading rate the failure strength and damage are less [6]. Laboratory CAT was performed with 0.02 $\mathrm{mm} / \mathrm{min}$ trying to maintain quasi-static state and to control and slow down the rupture process for closer investigation. CPM simulation was done with $0.05 \mathrm{~m} / \mathrm{sec}$ platen loading velocity. We choose $0.05 \mathrm{~m} / \mathrm{sec}$ loading rate for CPM simulation because it ensures quasi-static state throughout the loading process as proposed in [22]. However, recent model run indicates that CPM responds differently under much slower loading rate $(0.001 \mathrm{~m} / \mathrm{sec})$ showing less number of cracks and different load response, stable cracking that shows transition from fracturing to frictional sliding without stick-slip regime. Investigation on the effect of loading rate on damaging process under CAT configuration is left for future study.

The different load levels for mode I fracture development can also result from difference in the size (2D area) of clumps and the size of grains in Aue granite. In Fig.4a, the average size of the generated clumps (2D area) is $2.1 \mathrm{~mm}^{2}$. Zang [42] reported that average grain size of Aue granite is $1.35 \mathrm{~mm}$. Assuming that the grain size is equivalent to grain diameter, then average size (2D area) of Aue granite grain becomes $1.43 \mathrm{~mm}^{2}$, which is smaller than the average size of clumps (Fig.4a) by a factor of 1.5. By observing the distribution of 
cracks that were generated in CPM, distinctively clear mode I tensile fractures were observed that initiated at the point of stress concentration and propagated almost vertically downward. By comparing the load levels at the onset of the vertical mode I fracture in both CPM and BPM tested at same confining pressure of $0.1 \mathrm{MPa}$, it is checked that the required load level for mode I fracture initiation is generally greater in CPM than in BPM. Such result indicate that the larger the size of structural unit (average size of clumps in CPM is $2.1 \mathrm{~mm}^{2}$; average size of particles in BPM is $0.34 \mathrm{~mm}^{2}$ [31]), the higher the load level required to initiate mode I fracture. From laboratory mode I fracture tests using Chevron Bend method, Backers [39] reported $K_{I C}$ of Äspö diorite is $3.83 \pm 0.03 \mathrm{MPa} \sqrt{\mathrm{m}}$ which has average grain size of $1.28 \pm 1.16 \mathrm{~mm}$. It was reported that the $K_{I C}$ of Aue granite which has average grain size of $0.99 \pm 0.67 \mathrm{~mm}$ is $1.60 \pm 0.13 \mathrm{MPa} \sqrt{\mathrm{m}}$. Results from both numerical and laboratory experiments support that the larger the grain size, the higher the load required to initiate mode I fracture.

When the peak load is reached, the number of cracks in CPM is about 1000 whereas the number of $\mathrm{AE}$ in Aue granite is 5000 . This can also be explained by the size difference between clumps and rock grains. Larger number of cracks can be obtained when CPM is generated with higher resolution. Moreover, AE events detected in Aue granite involve not only pure tensile and pure shear events, but also involve events associated with grain boundary sliding, friction between loading platen and rock surface, and implosion sources such as pore collapse and grain crushing, all of which can contribute to the total number of $5000 \mathrm{AE}$.

Comparing Fig.7 and Fig.8, there appear two significant differences. Firstly, the inclined rupture path reaches the bottom right corner of the rock in case of CPM (Fig.7d), whereas the rupture in Aue granite stops $20 \mathrm{~mm}$ above the bottom platen. Such difference can again be explained by the difference in size of clumps and rock grains. In CAT simulation using bonded particle assembly with average particle size (2D area) of $0.34 \mathrm{~mm}^{2}$ under $10 \mathrm{MPa}$ 
confining pressure, the inclined rupture path did not reach the bottom but stops $40 \mathrm{~mm}$ above the bottom platen [31]. Another reason for the AE to stop above the bottom platen might be the effect of shear friction at the contact between rock and the steel loading platen which is not simulated in CPM.

Secondly, when we compare Fig.7d and Fig.8d, there appear cracks below the loading platen in CPM whereas there are no AE hypocenters detected below the loading platen. Such difference may be due to the fact that clump is rigid whereas rock grain can deform and be crushed. Stress that is applied by the loading platen and accumulated in the upper hanging wall body is progressively released as the inclined rupture develops through stages 1 to 3 (Fig.8a-c). When the rupture path is fully developed, the upper hanging wall body becomes free of stress and starts to slide over the foot wall body along the rupture surface, which consequently induces additional cracks highly localized along the rupture path (Fig.8d).

In Aue granite, as polarity analysis of the $\mathrm{AE}$ events indicates, shear sources and implosion sources prevail (crack source statistics in Fig.8d, 60\% S-type and 40\% C-type) in the frictional sliding regime, which are interpreted physically as pore collapse and grain crushing phenomena in the damage zone [18]. In CPM, however, due to the rough rupture path, the hanging wall and the foot wall blocks are likely to interlock, even after the rupture path is fully developed. The upper block is not free of load but stressed, and additional force is required to overcome sliding resistance at asperity-clumps along the rupture surface to make the hanging wall block slide over the foot wall block. Such mechanism results in additional increase in load and stick-slip type behaviour after the inclined rupture path is developed (Fig.11a). Eventually, interlocking of clumps after bond breakages is the fundamental process leading to (1) partially shear cracking and frictional sliding (stick-slip) along the rupture path, and (2) partially new crack formation in the upper hanging block below the loading platen not seen in AE hypocenter 
distribution.

There are also differences between the extent of damage zone visualized by crack distribution in CPM and by cloud of AE hypocenters in Aue granite, and by epoxy impregnation in thin sections of the deformed rock. The damage zone visualized in rock thin section by blue epoxy impregnation (Fig.9a-2) is narrower compared to those constructed by crack distribution in CPM (Fig.9b-2) and cloud of AE hypocenters (Fig.8). Differences in the geometry of the fracture process zone from AE hypocenters (Fig.8) and CPM crack distributions (Fig.7) can be explained by the occurrence of micro-failure mechanisms contributing to the AE cloud like intra-granular tensile cracks, grain breakage, pore collapse, grain crushing and degradation, which are not simulated in CPM.

In seismology, the Gutenberg-Richter $b$-value expresses the scaling relation between magnitude and frequency of earthquakes. Because $b$-values in space and time are discussed as a precursor phenomenon in earthquake prediction [55], $b$-values are determined in both, experimental and theoretical catalogues of events.

Scholz [56] studied the dependence of $b$-value on rock type, stress and confining pressure and claimed the stress state to be the deterministic factor of the $b$-value. In addition, the frequency-magnitude relation for events that accompanied frictional sliding and deformation of a ductile rock (marble) was found to have a higher $b$-value (1.5-2.5) than that observed in brittle Westerly granite (0.2-1.3). From Fig.11a, the same trend is evident from CPM simulations for the fracture and friction behavior of Aue granite. In the fracturing regime of Aue granite, the $b$ value before the first stress drop is low $(1.8<b<2.4)$ as compared to the $b$-value in the stick-slip and sliding regime of the rock $(2.6<b<3.0)$.

Amitrano [19] analyzed the $\mathrm{AE}$ and the mechanical behavior of Sidobre granite samples during triaxial compression tests. For different stages of the rock mechanical behavior 
(linear, nonlinear prepeak, nonlinear postpeak, shearing), there is a systematic decrease of the $b$ value with increasing confining pressure. Through FEM model based on a progressive isotropic damage, it was found that the $b$-value is controlled by variations of the internal friction angle induced by changes of the confining pressure.

Schorlemmer et al. [57] found that the $b$-value varies systematically for different styles of faulting: normal faulting events have the highest $b$-values, thrust events the lowest and strikeslip events intermediate values $\left(b_{\mathrm{TF}}<b_{\mathrm{SS}}<b_{\mathrm{NF}}\right)$. They implies that, given that thrust faults tend to be under higher stress than normal faults, the $b$-value can act as stress meter that depends inversely on differential stress.

Rao and Prasanna Lakshmi [51] performed a set of uniaxial compression tests on Godhra granite and monitored the acoustic emission, deformation and failure behavior. Their results indicated that during the early stages of loading, AE generated due to the closure and rubbing of pre-existing micro-cracks in the rock began to show a high $b$-value of $\sim 2.25$. It then decreased to $\sim 1.53$ and stabilized during the elastic deformation stage of the rock. At the end of that stage, dilatancy (inelastic volume change) begins due to the formation of a large number of new micro-cracks on the eventual fracture plane and showed $b$-value decrease down to $\sim 1.15$. They conclude that high $b$-values are caused by a large number of smaller amplitude AE that represents a state of new crack formation and slow crack growth, whereas low $b$-values indicate a state of relatively fast and unstable growing cracks documented in large amplitude AE.

The occurrence of cracks that have very small magnitudes in frictional sliding regime (Fig.11b, red and orange dots, $M=-7.5$ ) can be explained by analyzing the three energy terms monitored during CPM simulations - total strain energy, $E_{c}$, of the entire assembly stored at all contacts assuming a linear contact-stiffness model; total kinetic energy, $E_{k}$, of all particles accounting for both translational and rotational motion; total energy, $E_{f}$, dissipated by frictional 
sliding at all contacts. Frictional sliding regime is characterized by relatively small rate of events $(\Delta \mathrm{N} / \Delta \mathrm{t}<50)$ and continuous crack bursts compared to fracturing regime (Fig.11b). When a crack occurs, the stored strain energy at the contact is converted into kinetic energy (if cracking in tensile mode) or into combination of kinetic energy and frictional energy (if cracking in shear mode). Because the models are run dynamically with damping coefficient (that corresponds to seismic quality factor $Q$ of 200 for Aue granite), whenever crack occurs kinetic energy that causes contact force changes at the contacts surrounding the crack is reduced by a factor of the damping coefficient. Consequently, such chain reaction results in less amount of moment magnitude. The most efficient process to reduce kinetic energy in CPM is shear crack. This is because two contacting particles in shear produce energy dissipation by friction (Fig.2), and less kinetic energy accounts for smaller moment magnitude of cracks.

For CPM generation, contact bond tensile strength and shear strength are set to 100 $\mathrm{MPa}$ and $200 \mathrm{MPa}$, respectively. Such numbers are assigned considering the ratio of Mode I and Mode II fracture toughnesses $\left(K_{I I C} / K_{I C}\right)$ of Aue granite which is in range between 1.4 and 2.6 (Table 1). Potyondy and Cundall [22] developed a relation between contact bond tensile strength and $K_{I C}$ of a regularly bonded particle assembly, which is expressed as a function of average particle radius and contact bond tensile strength. Additional work is needed for $K_{I I C}$ and contact bond shear strength.

To evaluate the limits of our discrete element approach using CPM to reproduce confined fracture paths observed in Aue granite under different confining pressures, we monitored the internal stress state close to the kinking phenomenon observed (Fig.7c). For this purpose, the principal stress paths $\left(\sigma_{1}\right.$ vs. $\left.\sigma_{2}\right)$ were calculated from the local stress components $\left(\sigma_{\mathrm{xx}}, \sigma_{\mathrm{yy}}, \sigma_{\mathrm{xy}}\right)$ evolving in the monitoring circle (Fig.1d) for the CPM runs with 0.5 (Fig.12a) and $20 \mathrm{MPa}$ confining pressure (Fig.12b). Fig.12c presents the entire stress paths and the two 
rectangles indicate the $\sigma_{1}$ vs. $\sigma_{2}$ domains that are shown in Fig.12a and $12 \mathrm{~b}$.

At $0.5 \mathrm{MPa}$ confinement (Fig.12a), in the beginning of the CAT the ratio between maximum and minimum principal stresses $\left(\sigma_{1} / \sigma_{2}\right)$ is 24 . Principal stress ratio is plotted by grey dots (CPM path with numbers, arrows indicating increasing time) and by colour contours in the background. Both principal stresses increase as load increases (Fig.12a, vertical helix line made of grey dots). When the first crack occurs (CPM path, dot numbered -48), the minimum principal stress decreases and falls below zero (Fig.12a, $\sigma_{1}=72 \mathrm{MPa}, \sigma_{2}=-1.5 \mathrm{MPa}$ ) indicating tensile failure. Continued loading results in increase of minimum principal stress whereas the maximum principal stress remains rather constant (Fig.12a, $\left.\left(\sigma_{1}, \sigma_{2}\right)=(72,5)\right)$. During this stage (CPM path, dots numbered 11-12), fracture growth is characterized by vertical tensile cracks. At the end of CAT at $0.5 \mathrm{MPa}$ confining pressure, $\sigma_{1} / \sigma_{2}=11$ and the stress ratios are near the shearslip criterion $\left(\sigma_{1}=c+q \sigma_{3}\right.$ : where $\left.c=0, q=\left[\left(\mu^{2}+1\right)^{0.5}+\mu\right]^{2}, \mu=\tan \right)$ calculated from peak friction angle (Table 1 and Fig. $12 \mathrm{a}, \quad$ peak $=58^{\circ}$ ).

In case when the confining pressure is $20 \mathrm{MPa}$ (Fig.12b), in the beginning $\sigma_{1} / \sigma_{2}=7$, and both principal stresses increase until first crack occurs $\left(\sigma_{1} / \sigma_{2} \approx 10\right)$. There is also a period where the minimum principal stress decreases, i.e. from 12 to $7 \mathrm{MPa}$, while the maximum principal stress shows little change, i.e. 100-105 MPa. This period is characterized by generation of both tensile and shear cracks within the monitoring circle (CPM path, dot numbered 14). Shear cracks that are inclined and connecting the vertically aligned tensile cracks make the stress path more fluctuating compared to the case when the confining pressure is 0.5 MPa. After crack generation, the principal stresses increase $\left(\sigma_{1}, \sigma_{2}\right)=(130,13)$ indicating that the bonded clumps in the monitoring circle can sustain further loading without inducing crack because of the confining pressure (almost the same slope of the stress path, $\Delta \sigma_{1} / \Delta \sigma_{2} \approx 40$ ). When the asymmetric load reaches its peak, then minimum principal stress starts to increases 
significantly (from 13 to $22 \mathrm{MPa}$ ), while the maximum principal stress is almost constant (125 $\mathrm{MPa}$ ). This stage is characterized by the generation of equal portions of tensile and shear cracks, which fill the inclined shear band in the model at high (> $10 \mathrm{MPa}$ ) confining pressure (Fig.9b-3). The stress ratio is 6-7 at the very end of the CAT with $20 \mathrm{MPa}$ confining pressure (Fig.12b, grey dots numbered 6-7).

In Fig. 12b, three Mohr-Coulomb based shear-slip criteria are plotted by dashed lines. The first criterion plotted by using the peak friction angle $\left(58^{\circ}\right)$ of CPM determines whether a given stress state $\left(\sigma_{1}\right.$ vs. $\left.\sigma_{2}\right)$ causes virgin fracture. As seen in Fig.12b, there appear a few points sitting left side of the $58^{\circ}$ shear-slip criterion $\left(\sigma_{1}=100-105 \mathrm{MPa}, \sigma_{2}<8 \mathrm{MPa}\right)$. Cracking at those stress states is explained by virgin fracturing which consists of vertically aligned tensile cracks and a few inclined shear cracks inter-connecting the tensile cracks. After a virgin fracture occurs, the principal stresses fall into the region between the $58^{\circ}$ and $51^{\circ}$ shear-slip criteria. When the maximum principal stress reaches $130 \mathrm{MPa}$ (peak load), a large number of cracks appear in the monitoring circle producing a significant change in minimum principal stress. At the final part of the stress path, both principal stresses decreases and the points are aligned in the region between the $51^{\circ}$ and $42^{\circ}$ shear-slip criteria calculated from the residual friction angles (Table 1). It is speculated that shear cracks generated in the frictional sliding regime build up a process zone in which the hanging wall block slides over the foot wall block. While sliding, residual strength is built up in the process zone that is composed of frictional resistance at shearbroken contacts and resistance against translational and rolling motions of asperity-clumps over one another along the fracture/friction plane. This is why principal stress ratios are plotted between the two shear-slip criteria computed from the residual friction angles at the very end of the CAT simulation with $20 \mathrm{MPa}$ confining pressure.

In the past, various numerical techniques have been employed to reproduce the fracture 
paths in rock under low, intermediate and high confining pressures [21]. Yoon [31] demonstrated that use of DEM based bonded particle model was partially successful in reproducing the fracture paths of granite under confined asymmetric loading compared to FEM based model. Use of CPM made the simulated fracture propagation path match far closer to the laboratory observations. Remaining differences can be explained by (1) other micro-failure mechanism, e.g. intra-granular cracks (grain breakage/crushing) not simulated in CPM, (2) local variation of friction coefficients under confining pressure and pressure dependent rock fracture toughnesses (mode I and mode II) and also mixed-mode failure processes, (3) difference between CPM microstructure and real rock structure. DEM based rock modeling by Potyondy [58] and Groh et al. [59] show that replicating true microstructure and microstructural interactions of rock enable modeling of complex and non-linear behaviors of crystalline rocks by DEM. In particular, the use of grain-based model [58] is one promising approach to match fracture path in heterogeneous, brittle rock-like materials from experiments and numerical simulations.

In future studies, other numerical methods like BEM, DDA, DFN, x-FEM [60] should be applied to simulate and validate the unique fracture paths in our laboratory CAT benchmark test for different confining pressures. 


\section{Conclusions}

Laboratory confined asymmetric test (CAT) on Aue granite was simulated using the discrete element method (DEM) based clumped particle model (CPM). Experimental results which include locations of acoustic emission hypocenters and damaging sequence, fracture propagation path and its dependence on confining pressure are compared with those from CPM simulations. In addition, temporal changes of the Gutenberg-Richter $b$-values during the damaging sequence were simulated and compared with experimental results available from literature.

In CPM simulations the load drop caused by mode I rupture (sub-vertical fracture consists of mainly tensile source) nucleus occurs at 0.82 of failure time (at $90 \%$ of peak load), while in laboratory CAT with $10 \mathrm{MPa}$ confinement the load drop associated with mode I rupture occurs at 0.56 of normalized failure time (at $70 \%$ of peak load). Such discrepancy can be explained by (1) different loading rates, and (2) size and strength differences between clumps and rock grains. In faster laboratory loading rate, the rock specimen exhibit higher strength. From numerical simulation we infer that the larger the grain size, the higher the load level required to initiate mode I fracture.

Locations of acoustic emission hypocenters in Aue granite generated during fracturing and frictional sliding stages were compared with the simulation results. CPM crack pattern fit the observed cloud of AE detected in the laboratory CAT with $10 \mathrm{MPa}$ confinement in a sense that four stages of rupture growth could be validated. Events first occur below the asymmetric steel loading plate acting as stress concentrator (stage 1), propagate vertically downward mainly by tensile cracking (stage 2 ) and then develop a prominent $30-40^{\circ}$ kink (stage 3 ). In the friction regime (stage 4), the CPM dissects causing sliding of the upper hanging block over the lower one. 
Confined rupture path visualized from CPM crack patterns and laboratory CAT core inspection are in good agreement in a sense that at low confining pressure $(<5 \mathrm{MPa})$, the first crack cluster appears below the stress concentrator (asymmetric steel loading platen). With increasing load, the cluster propagates vertically downward and progressively changes its direction towards the non-loaded portion of the model causing splitting failure consisted of mainly tensile cracks. Increase in confining pressure (10, $40 \mathrm{MPa})$ suppresses rock splitting and results in more localized shear rupture paths entering into the loaded portion of the model. The percentage of simulated shear cracks increases from $24 \%$ at $10 \mathrm{MPa}$ to $45 \%$ at $40 \mathrm{MPa}$.

Interlocking of asperity-clumps after bond breakages may be the fundamental difference for AE not observed below the asymmetric loading plate in the Aue granite and CPM cracks occurring in the hanging wall below the stress concentrator. To what extent the interlocked asperity-clumps may support processes in natural earthquake mechanics is not yet clear, because AE, CPM cracks and core-inspected fracture pattern do not necessarily account for the same micro-processes active during rock failure. Differences in the geometry of the fracture damage zone from AE hypocenters and CPM crack distributions, however, can be explained by the occurrence of micro-failure mechanisms other than simulated in the CPM, like intra-granular grain breakage and grain crushing.

Moment magnitudes of crack source are plotted with cumulative frequency (in log scale) to obtain Gutenberg-Richter $b$-values in the CAT of CPM with $10 \mathrm{MPa}$ confinement. We observed that $b$-values are relatively lower during virgin fracturing and gradually increase as the model undergoes stick-slip and frictional sliding type post-failure. This is consistent with experimental observations by Main et al. [52] and Sammonds et al. [53] on sandstones at 50 MPa confining pressure. Bursts in crack events (avalanche cracking) have large magnitudes $(M=-4)$ and are restricted mostly to the fracturing regime. In the stick-slip and frictional sliding 
regimes, cracks are characterized by very small magnitude events $(M=-7.5)$, which is also consistent with experimental findings [51-54]. Within the CPM, shear cracking is the most efficient way to reduce the kinetic energy of events, and therefore to produce small magnitude events.

Different fracture paths under various confining pressures were investigated by monitoring temporal changes of principal stresses at where the rupture path is expected to change its direction quickly over short distance. At relatively low confining pressure, as crack gradually appears, the minimum principal stress falls below zero indicating that crack development leads to tensile failure accompanied by growth of sub-vertically oriented tensile cracks. At higher confining pressure, the stress path exhibits a period where the minimum principal stress shows sudden drop documented by generation of vertically aligned tensile cracks. Confining pressure prevents growth of vertical tensile fracture and enhances the development of an inclined process zone where equal portion of tensile and shear cracks are formed. Ratio of principal stresses was found to vary in a relatively narrow range in case of failure by shear cracking compared to a failure by tensile cracking. We claim this method of monitoring circle (sphere) in 2D (3D) principal stress space to be a powerful tool in analyzing the micro-mechanics of rock fracture and friction in further studies. Please refer to this method as the local stress monitoring approach (LSM). 


\section{Acknowledgment}

This study initiated in 2008 from development of clumped particle model when first author was a post-doc in Seoul National University which was financially supported by Brain Korea 21 Division of Energy and Resource Engineering. We would like to thank Prof. Seokwon Jeon (SNU) for his contribution in early stage of this research regarding development and testing of clumped particle model. Second author was supported by the European Union funded project GEISER (Geothermal Engineering Integrating Mitigation of Induced Seismicity in Reservoirs, \#940029) while working on the manuscript, and would like to thank Ernst Huenges and David Bruhn (GFZ) for their support. We would like to thank Dr. J. Hazzard (Itasca USA) for allowing us to use the seismicity modeling functions and Dr. D. Potyondy (Itasca USA) for his review and comments on the results of clumped particle model simulation. Several anonymous reviewers are also very much thankful for their valuable comments which enriched the content of manuscript. 


\section{References}

[1] Scholz CH. Earthquakes and friction laws. Nature 1998;391: 37-42.

[2] Bawden GW, Michael AJ, Kellogg LH. Birth of a fault: connecting the Kern County and Walker Pass. California earthquakes. Geology 1999;27:601-604.

[3] Lockner DA, Byerlee JD, Kuksenko V, Ponomarev A, Sidorin A. Quasi-static fault growth and shear fracture energy in granite. Nature 1991;350:39-42.

[4] Spetzler H, Sobolev G, Koltsov A. Zang A, Getting IC. Some properties of unstable slip on irregular surfaces. PAGEOPH 1991;137:95-112

[5] Lockner DA. The role of acoustic emission in the study of rock fracture. Int J Rock Mech Min Sci Geomech Abstr 1993;30:883-899.

[6] Lockner DA. Rock failure. In: Rock Physics \& Phase Relations: A Handbook on Physical Constants, TJ Ahrens, ed. AGU, 1995, pp 127-147.

[7] Lei X, Kusunose K, Rao MVMS, Nishizawa O, Satoh T. Quasi-static fault growth and cracking inhomogeneous brittle rock under triaxial compression using acoustic emission monitoring. J Geophys Res 2000;105(B3):6127-6139.

[8] Zang A, Wagner FC, Stanchits S, Janssen C, Dresen G. Fracture process zone in granite. J Geophys Res 2000;105(B10):23651-23661.

[9] Lei X, Sato T. Indicators of critical point behavior prior to rock failure inferred from prefailure damage. Tectonophysics 2007;431:97-111.

[10] Dieterich JH. Time-dependent friction in rock. J Geophys Res 1972;77:3690-3697.

[11] Okubu PG, Dietrich JH. Effect of physical fault properties on frictional instabilities produced on simulated faults. J Geophys Res 1984;89(B7):5817-5827.

[12] Dieterich JH. Earthquake nucleation of faults with rate- and state-dependent strength. Tectonophysics 1992;211:115-134. 
[13] Marone C. The effect of loading rate on static friction and rate of fault healing during the earthquake cycle. Nature 1998;391:69-72.

[14] Rathbun AP, Marone C, Alley RB, Anandakrishnan S. Laboratory study of the frictional rheology of sheared till. J Geophys Res 2008;113:F02020.

[15] Yabe Y. Evolution of source characteristics of AE events during frictional sliding. Earth Planets Space 2008;60:e5-e8.

[16] Rathbun AP, Marone C. Effect of strain localization on frictional behaviour of sheared granular materials. J Geophys Res 2010;115:B01204.

[17] Liakopoulou-Morris F, Main IG, Crawford BR, Smart BGD. Microseismic properties of a homogeneous sandstone during fault nucleation and frictional sliding. Geophys J Int 1994;119:219-230.

[18] Zang A, Stanchits S, Dresen G. Acoustic emission controlled triaxial rock fracture and friction tests. In: Structural Integrity and Fracture, AV Dzskin, X Hu, E Sahouryeh, ed. Lisse: Swets \& Zeitlinger, 2002, pp 289-294.

[19] Amitrano D. Brittle-ductile transition and associated seismicity: Experimental and numerical studies and relationship with the $b$ value. J Geophys Res 2003;108(B1):2044.

[20] Zang A, Wagner FC, Stanchits S, Dresen G, Andresen R, Haidekker MA. Source analysis of acoustic emissions in Aue granite cores under symmetric and asymmetric compressive loads. Geophys J Int 1998;135:1113-1130.

[21] Dumstorff P, Yoon J, Zang A, Dresen G, Meschke G. Numerical simulation of crack paths in laboratory compressed Aue granite. Geophys Res Abstr 2006;8:07361.

[22] Potyondy DO, Cundall PA. A bonded-particle model for rock. Int J Rock Mech Min Sci 2004;41:1329-1364.

[23] Cundall PA, Strack ODL. A discrete numerical model for granular assemblies. 
Geotechnique 1979;29:47-65.

[24] Potyondy DO, Cundall PA, Sarracino RS. Modeling of shock-and gas-driven fractures induced by a blast using bonded assemblies of spherical particles. In: Rock Fragmentation by Blasting, Proceedings of the 5th International Symposium on Rock Fragmentation by Blasting - FRAGBLAST 5, B Mohanty, ed. Rotterdam: Balkema, 1996, pp 55-62.

[25] Potyondy DO, Cundall PA. Modeling notch-formation mechanisms in the URL Mine-by test tunnel using bonded assemblies of circular particles. Int J Rock Mech Min Sci $1998 ; 35: 510-511$

[26] Hazzard JF, Young RP. Simulating acoustic emissions in bonded-particle models for rock. Int J Rock Mech Min Sci 2000;37:867-872.

[27] Kulatilake PHSW, Malama B, Wang J. Physical and particle flow modeling of jointed rock block behavior under uniaxial loading. Int J Rock Mech Min Sci 2001;38:641-657.

[28] Hazzard JF, Young RP, Oates SJ. Numerical modelling of seismicity induced by fluid injection in a fractured reservoir. In: Mining and Tunnel Innovation and Opportunity, Proceedings of the 5th North American Rock Mechanics Symposium, 2002, pp 10231030.

[29] Holt RM, Kjølaas J, Larsen I, Li L, Goutusso Pillitteri A, Sønstebø EF. Comparison between controlled laboratory experiments and discrete particle simulations of the mechanical behaviour of rock. Int J Rock Mech Min Sci 2005;42:985-995.

[30] Potyondy DO. Simulating stress corrosion with a bonded-particle model for rock. Int J Rock Mech Min Sci 2007;44:677-691.

[31] Yoon J. Application of experimental design and optimization to PFC model calibration in uniaxial compression simulations. Int J Rock Mech Min Sci 2007;44:871-889.

[32] Wanne TS, Young RP. Bonded-particle modelling of thermally fractured granite. Int J 
Rock Mech Min Sci 2008;45:789-799.

[33] Park J, Song J. Numerical simulation of a direct shear test on a rock joint using a bondedparticle model. Int J Rock Mech Min Sci 2009;46:1315-1328.

[34] Yoon J, Jeon S. Use of modified particle-based method in simulating blast-induced rock fracture. In: Rock Fragmentation By Blasting, Proceedings of the 9th International Symposium on Rock Fragmentation by Blasting - FRAGBLAST 9, JA Sanchidrián, ed. Wiltshire: CRC Press/Balkema, 2010, pp 371-380.

[35] Cho N, Martin CD, Sego DC. A clumped particle model for rock. Int J Rock Mech Min Sci 2007;44:997-1010.

[36] Yoon J, Jeon S, Stephansson O, Zang A. Testing of clumped particle models in simulation of laboratory rock fractures in compression. In: Fracture of Materials and Structures from Micro to Macro Scale, Proceedings of the 18th European Conference on Fracture, Klingbeil D, Vormwald M, Eulitz KG, ed. Berlin: DVM Deutscher Verband Für Material Forschungs und Prüfung E.V., 2010, C.06.1-5.

[37] Yoon JS, Jeon S, Zang A, Stephansson O. Bonded particle model simulation of laboratory rock tests for granite using particle clumping and contact unbonding. In: Continuum and distinct element numerical modeling in geomechanics, Proceedings of 2nd International FLAC/DEM Symposium, 2011.

[38] Tischendorf G, Geisler M, Gerstenberger H, Budzinski H, Vogler P. Geochemie der variszischen Granite des Westerzgebirges/Vogtland - Ein Beispiel für zinnlagerstättengenerierende Granite. Chemie der Erde 1987;46:213-235.

[39] Backers T. Fracture toughness determination and micromechanics of rock under Mode I and Mode II loading. 2004, PhD dissertation, University of Potsdam, Germany.

[40] Backers T, Stephansson O, Rybacki E. Rock fracture toughness testing in Mode II - 
punch-through shear test. Int J Rock Mech Min Sci 2002;39:755-769.

[41] Backers T, Dresen G, Rybacki E, Stephansson O. New data on mode II fracture toughness of rock from the Punch-Through Shear test. Int J Rock Mech Min Sci 2004;41(Supplement 1):2-7.

[42] Zang A. Akustische Emissionen beim Sprödbruch von Gestein. 1997, Habilitationsschrift, Scientific Technical Report STR97/19, University of Potsdam, Germany.

[43] Chang SH, Lee CI. Estimation of cracking and damage mechanisms in rock under triaxial compression by moment tensor analysis of acoustic emission. Int J Rock Mech Min Sci 2004,41:1069-1086.

[44] Eberhardt E, Stead D, Stimpson B. Quantifting progressive pre-peak brittle fracture damage in rock during uniaxial compression. Int J Rock Mech Min Sci 1999;36:361-380.

[45] Schöpfer MPJ, Abe S, Childs C, Walsh JJ. The impact of porosity and crack density on the elasticity, strength and friction of cohesive granular materials: Insights from DEM modelling. Int J Rock Mech Min Sci 2009;46:250-261.

[46] Hazzard JF, Young RP. Moment tensors and micromechanical models. Tectonophysics 2002;356:181-197.

[47] Hazzard JF, Young RP. Dynamic modeling of induced seismicity. Int J Rock Mech Min Sci 2004;41:1365-1376.

[48] Ilyas A. Estimation of Q factor from seismic reflection data. 2010, Report GPM6/09, Curtin University of Technology, Australia.

[49] Feustel AJ. Seismic attenuation in underground mines: measurement techniques and applications to site characterization. 1995, PhD thesis, Queen's University, Kingston, Ontario, Canada.

[50] Gutenberg B, Richter CF. Seismicity of the Earth and Associated Phenomena 2nd ed. 
Princeton: Princeton Univ. Press, 1954.

[51] Rao MVMS, Prasanna Lakshmi KJ. Analysis of $b$-value and improved $b$-value of acoustic emissions accompanying rock fracture. Current Science 2005;89(9):1577-1582.

[52] Main IG, Meredith PG, Jones C. A reinterpretation of the precursory seismic $b$-value anomaly from fracture mechanics. Geophys J 1989;96:131-138.

[53] Sammonds PR, Meredith PG, Main IG. Role of pore fluids in the generation of seismic precursors to shear fracture. Nature 1992;359:228-230.

[54] Sammonds P, Ohnaka M. Evolution of microseismicity during frictional sliding. Geophys Res Let 1998;25(5):699-702.

[55] Wyss M. Evaluation of proposed earthquake precursors. American Geophysical Union, Washington DC, 1991.

[56] Scholz CH. The frequency-magnitude relation of micro-fracturing in rock and its relation to earthquake. Bull Seismol Soc Am 1968;58(1):399-415.

[57] Schorlemmer D, Wiemer S, Wyss M. Variations in earthquake-size distribution across different stress regimes. Nature 2005;437:539-542.

[58] Potyondy DO. A grain-based model for rock: Approaching the true microstructure. In: Rock Mechanics in the Nordic Countries 2010, Proceedings of Bergmekanikk I Norden 2010, CC Li, ed. Kongsberg: Norwegian Group for Rock Mechanics, 2010.

[59] Groh U, Konietzky H, Walter K, Herbst M. Damage simulation of brittle heterogeneous materials at the grain size level. Theor Appl Fract Mech 2011;55:31-38.

[60] Jing L, Stephansson O. Fundamental of discrete element methods for rock engineering theory and applications. Developments in Geotechnical Engineering 85, Elsevier, 2007. 


\section{Figures}

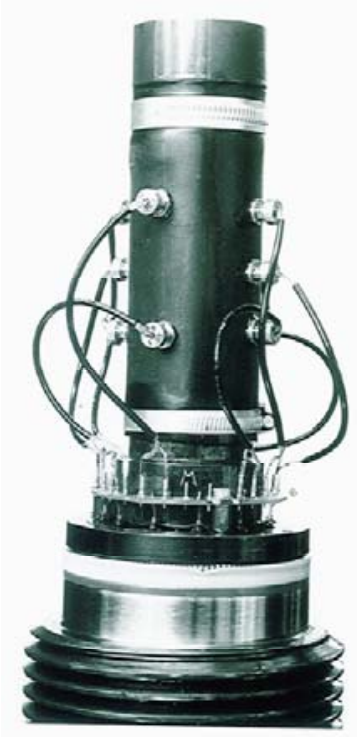

(a)

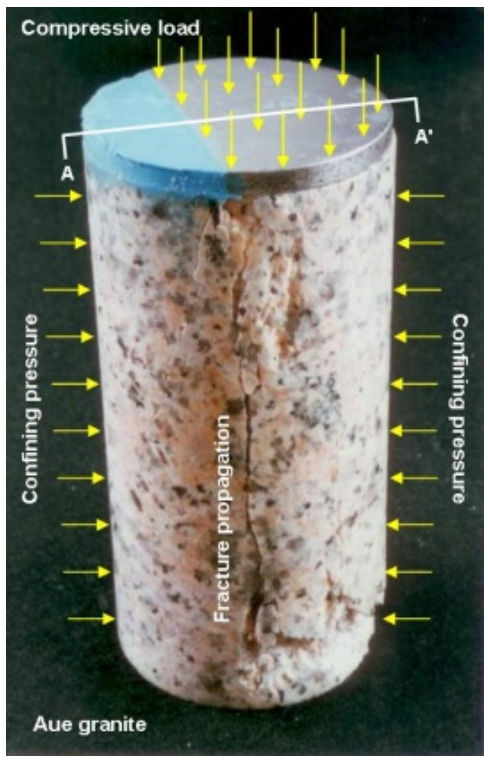

(c)

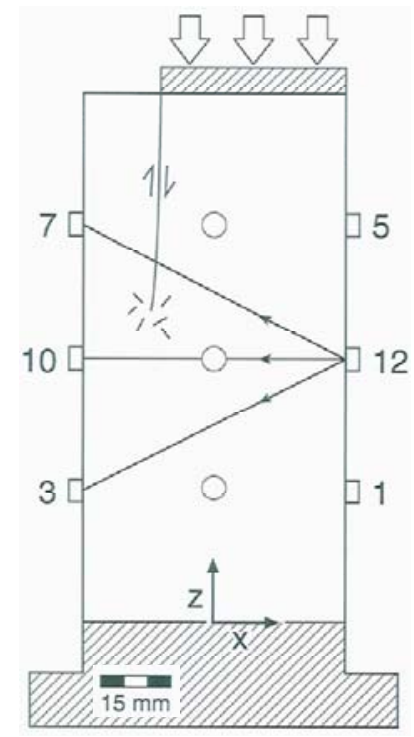

(b)

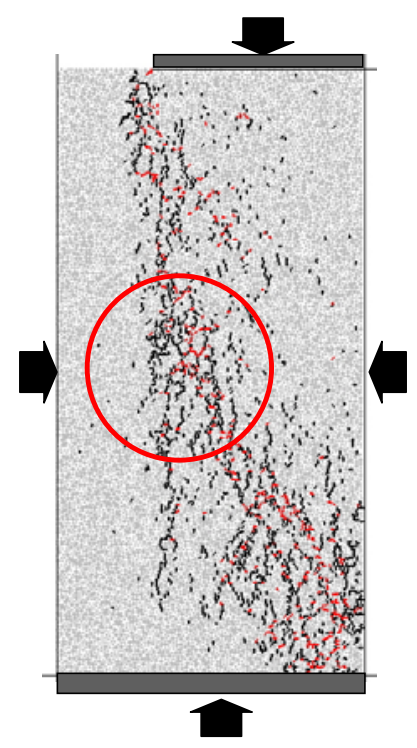

(d)

Figure 1. (a) Laboratory sample setup of confined asymmetric test (CAT) with acoustic emission sensors. (b) Schematic view of CAT loading configuration (in 2D) indicating shear rupture and process zone related cracks (short bars) ahead of the rupture tip. (c) Photographic $3 \mathrm{D}$ view of deformed CAT core after test. (d) Clumped particle model after failure with tensile (black) and shear (red) cracks visualized. Black arrows indicate loading configuration. Stress components $\left(\sigma_{\mathrm{x}}, \sigma_{\mathrm{y}}, \sigma_{\mathrm{xy}}\right)$ evolving within red circle as model undergoes deformation are measured throughout the loading to compute principle stresses $\left(\sigma_{1}, \sigma_{2}\right)$ for shear-slip analysis. 


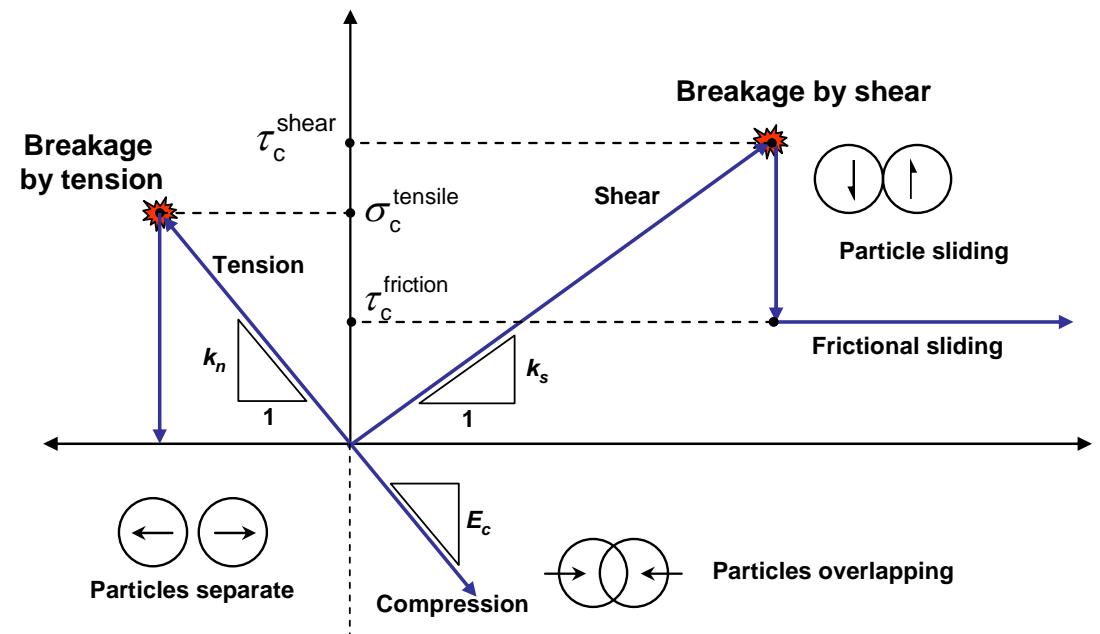

Figure 2. Force-displacement behavior for contact occurring at a point between two particles and definitions of micro-parameters listed in Table 2. Modified from [35]. 


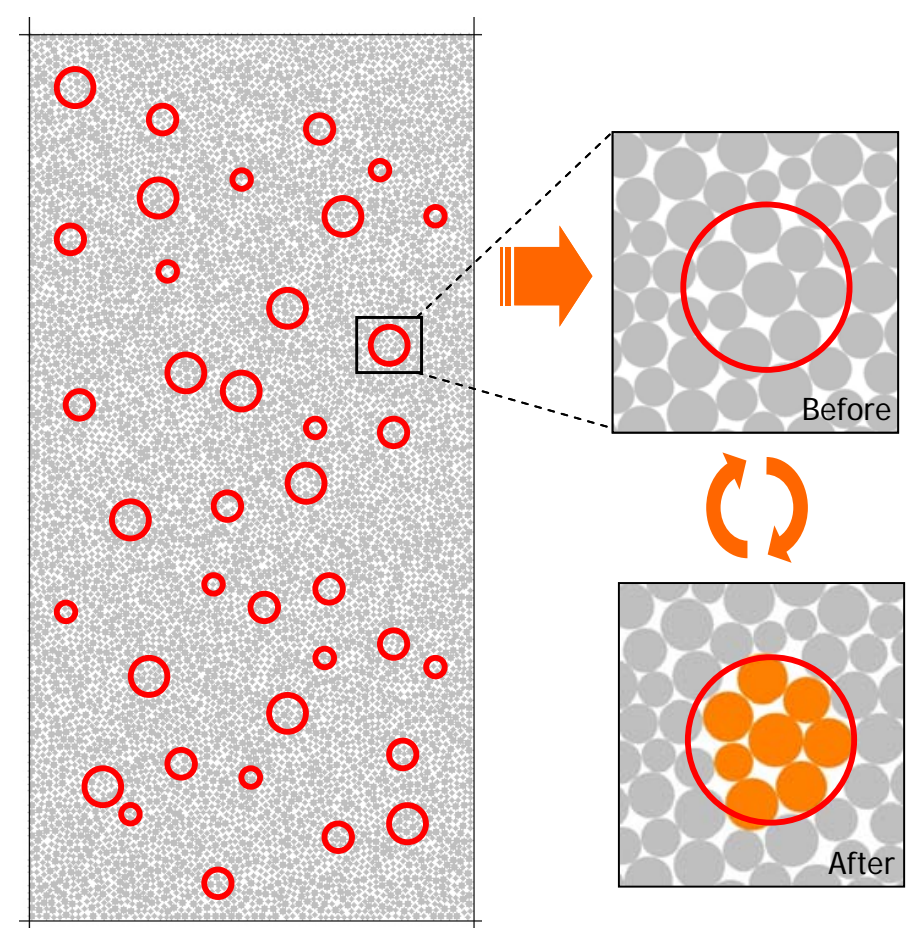

(a)

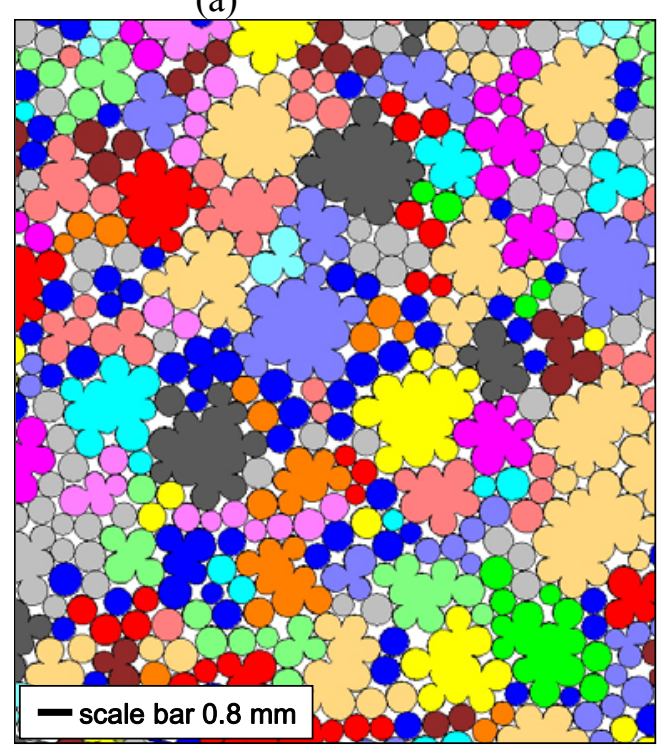

(d)

(b)

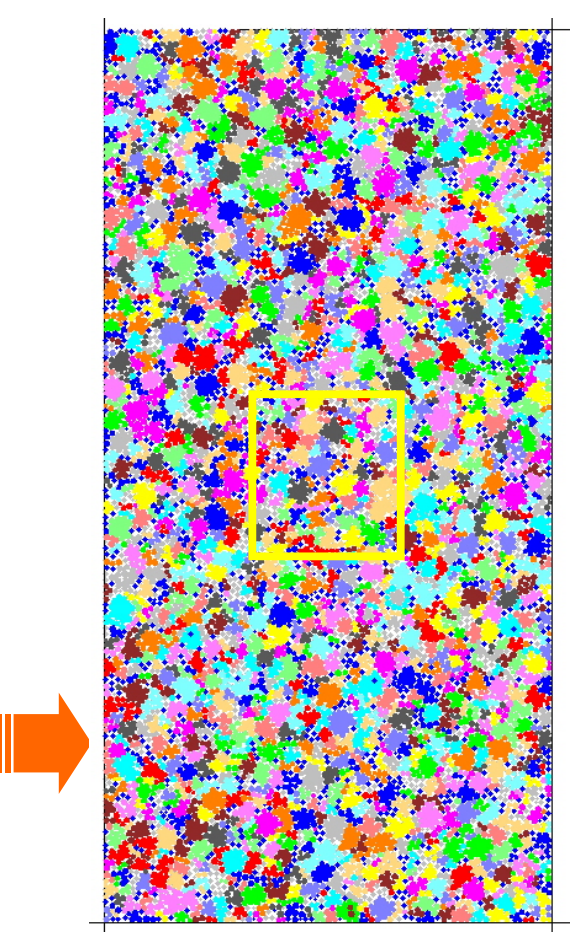

(c)

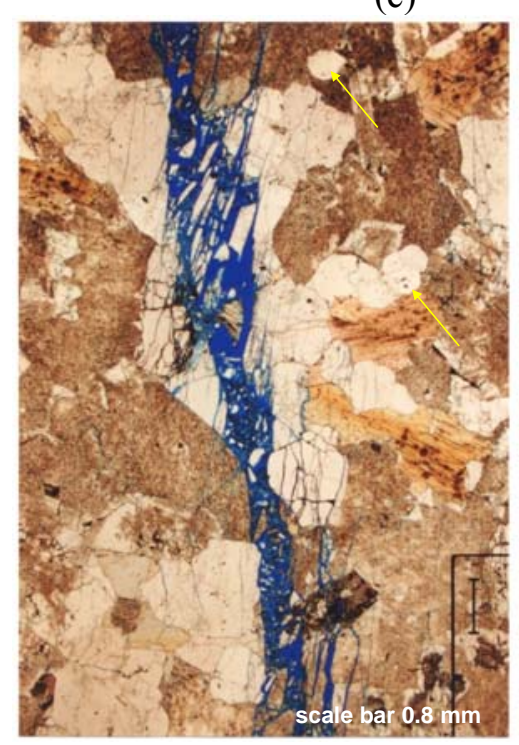

(e)

Figure 3. (a) Bonded particle model with randomly placed circular stamps of different radii, (b) A group of neighboring particles enclosed by a circle is combined into a rigid clump, (c) Clumped particle model after the stamping algorithm is terminated, (d) Close-up view of the clumped particle model (yellow box in (c)), (e) Close view on thin section of deformed Aue granite showing grain structure and en échelon fractures. Impregnated epoxy is denoted in blue. 


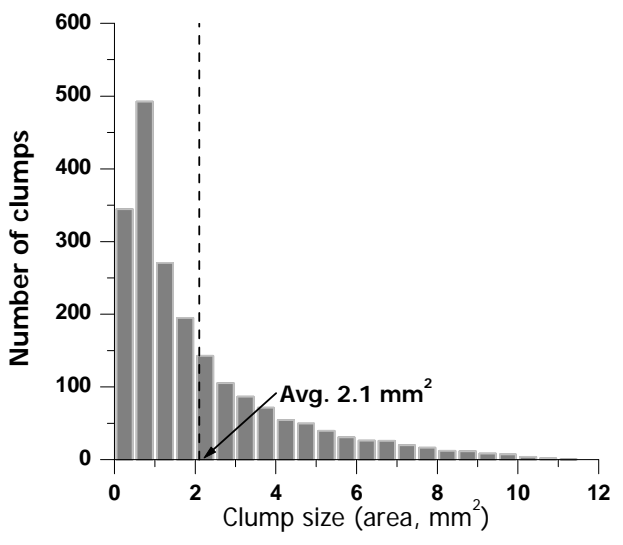

(a)

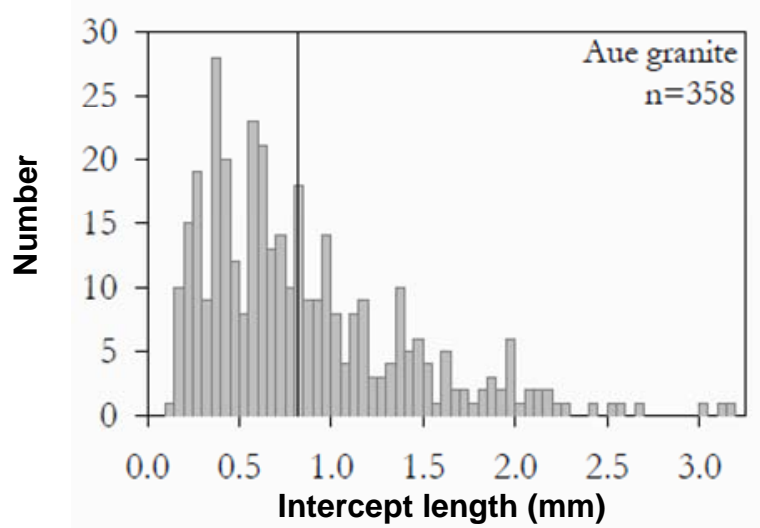

(b)

Figure 4. (a) Size (2D area) distribution of clumps, (b) distribution of intercept length measured on thin section of Aue granite (red syeno-monzo-granite) [39]. 


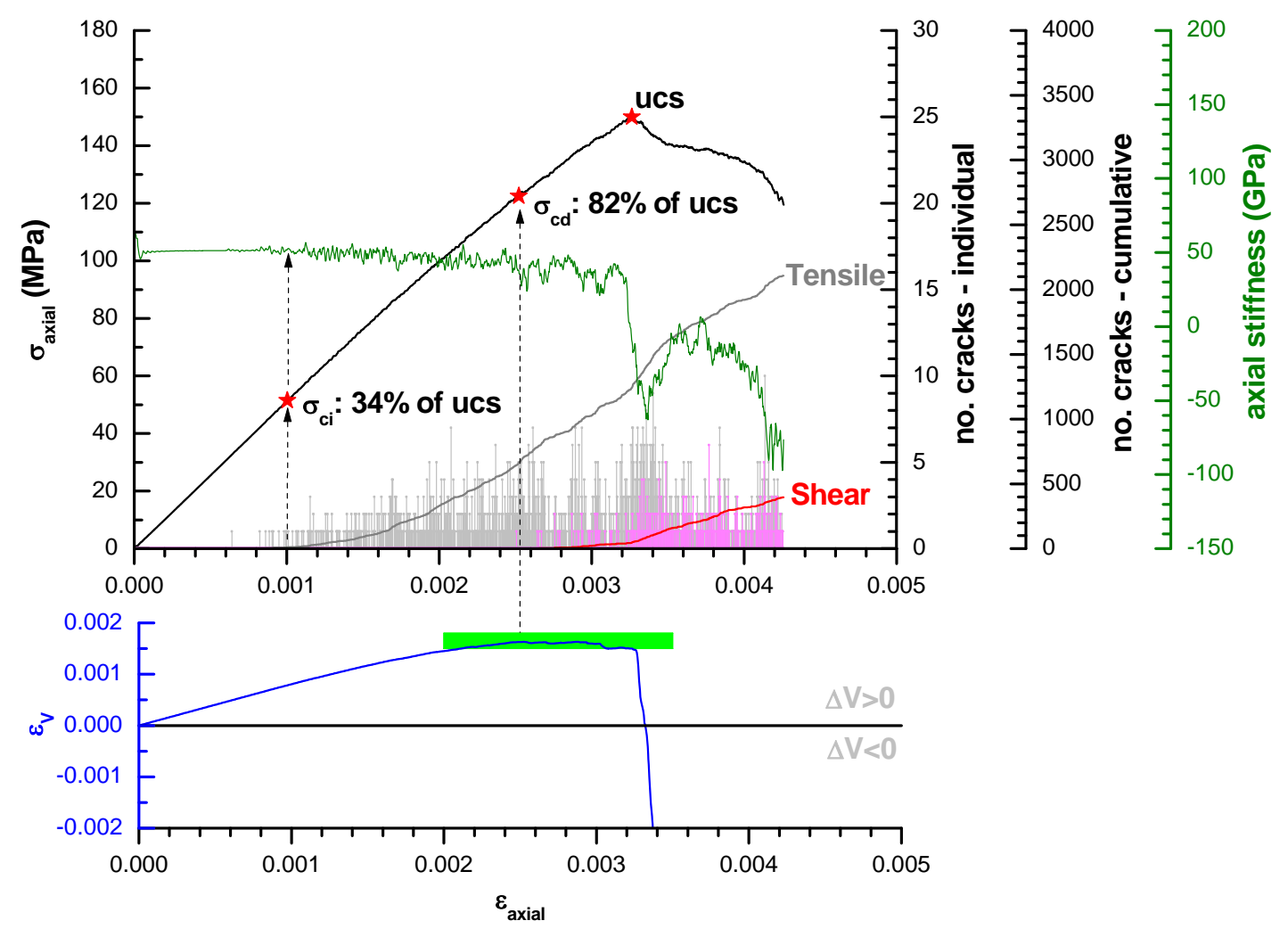

(a)

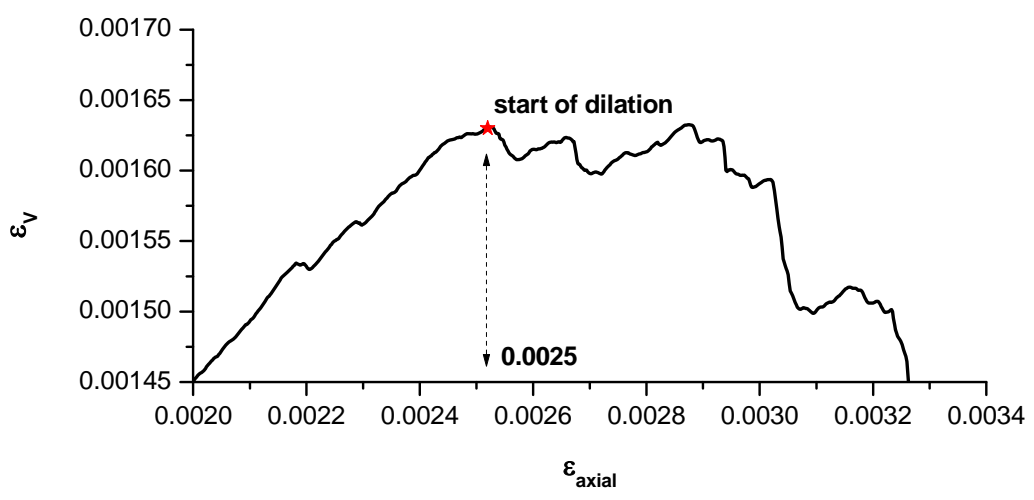

(b)

Figure 5. (a) Variation of axial stress, axial stiffness, number of cracks (individual events and cumulative events) and volumetric strain vs. axial stain curves of clumped particle model tested under uniaxial compression. Crack-initiation stress $\left(\sigma_{\mathrm{ci}}\right)$ and crack-damage stress $\left(\sigma_{\mathrm{cd}}\right)$ occur at $34 \%$ and $82 \%$ of uniaxial compressive strength. (b) Close-up view of the box area in volumetric strain vs. axial strain curve in (a). The point where crack-damage stress level is defined is denoted by star mark indicating start of dilation. 

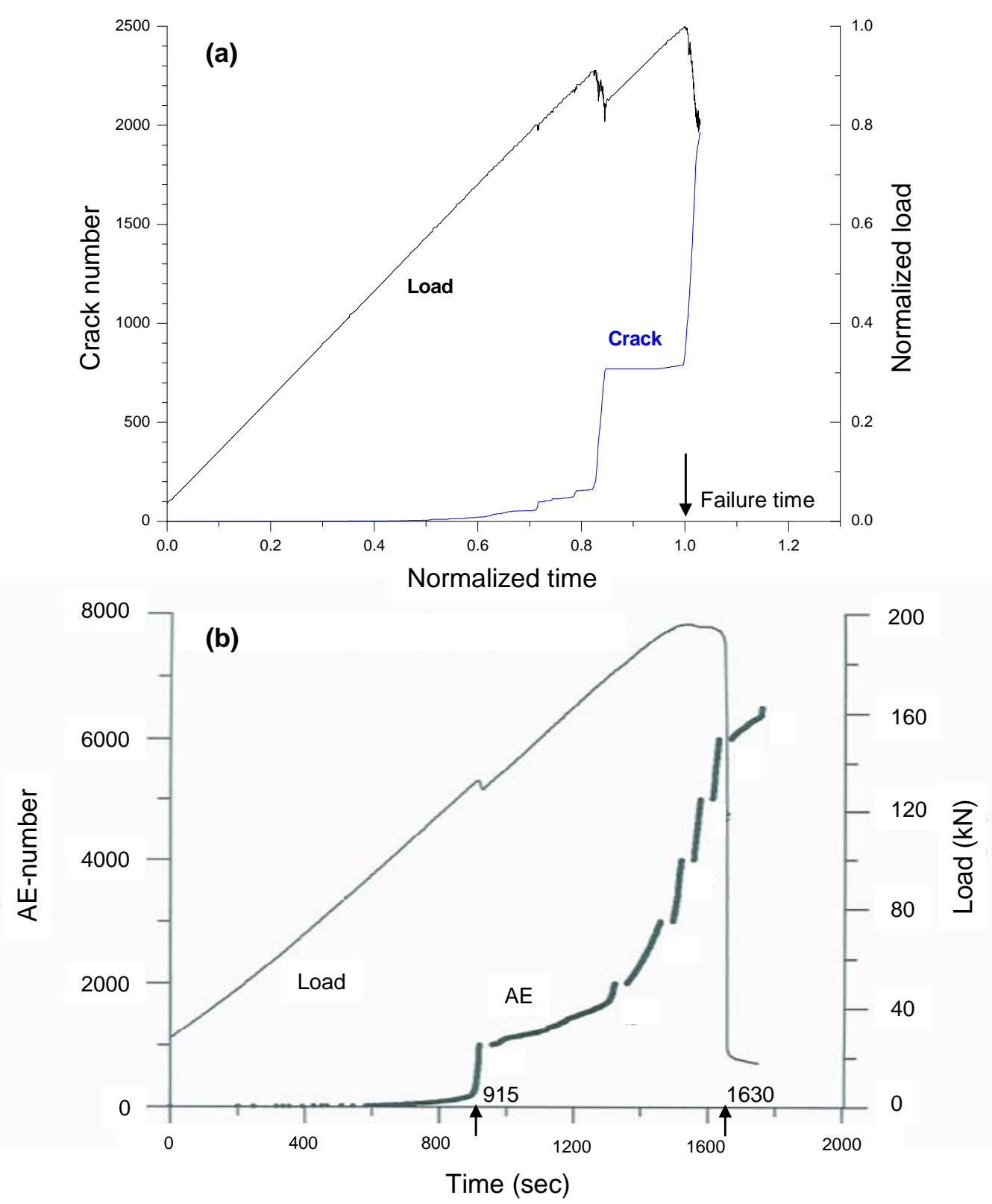

Figure 6. Load vs. time curve for (a) numerical simulation with clumped particle model, and (b) laboratory confined asymmetric test (CAT. In (a) load and time is normalized and cracks are identified with bond breakage. In (b) load and time are absolute values from experiment and cracks are identified with acoustic emissions (AE) recorded with piezo-ceramic sensors. 


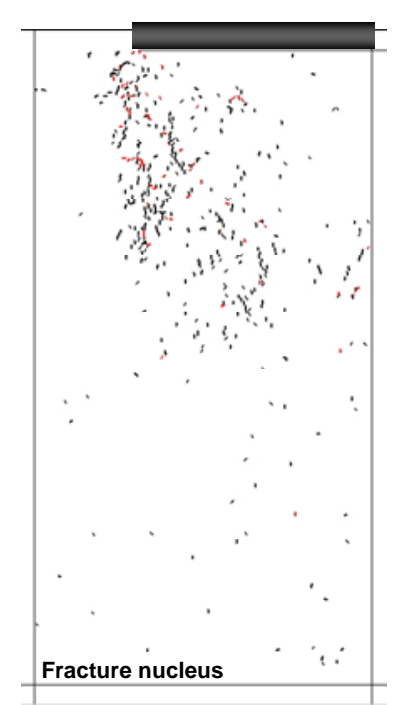

(a) Stage 1

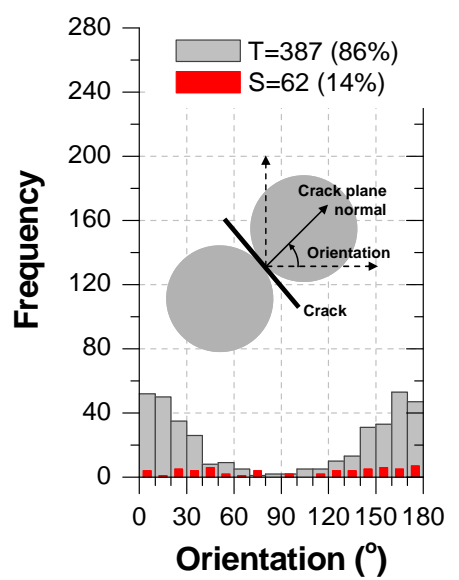

(e) Stage 1

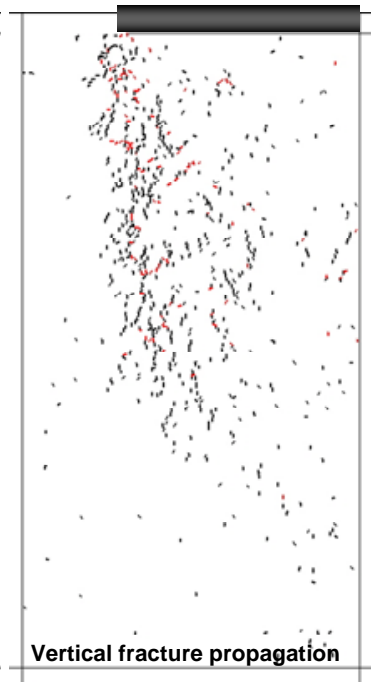

(b) Stage 2

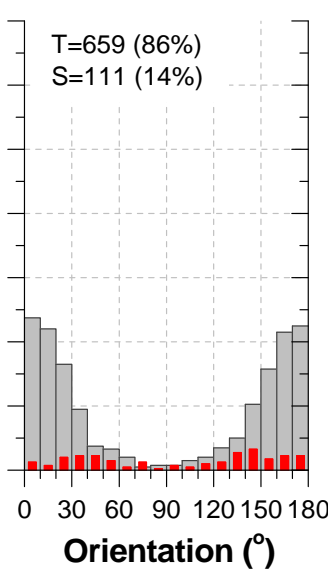

(f) Stage 2

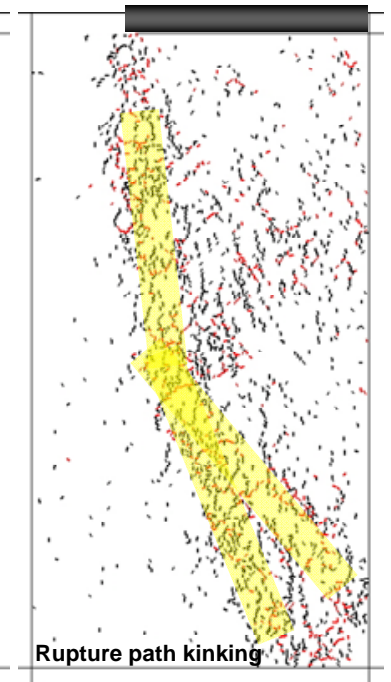

(c) Stage 3

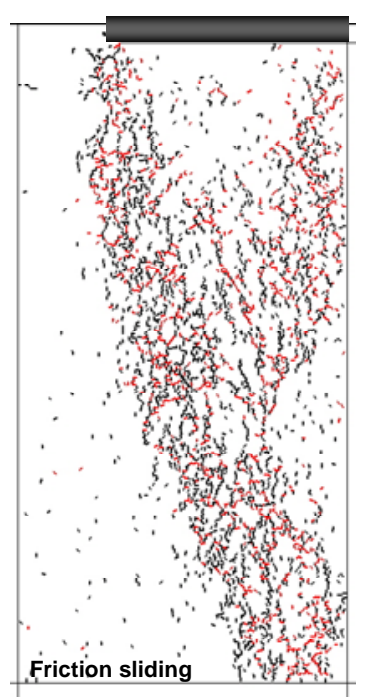

(d) Stage 4

Figure 7. Growth of rupture path (cumulative distribution of cracks; black: tensile, red: shear) in CPM simulated at $10 \mathrm{MPa}$ confining pressure divided into four stages (a-d). Orientation distribution of crack plane normals (tensile $=$ gray bar, shear $=$ red bar) for corresponding deformation stages (e-h). Total number of cracks and relative portions are documented in the histograms. Inlet figure in (e) describes definition of orientation of crack plane normal which is positive when counted anticlockwise from positive $\mathrm{x}$-axis. 

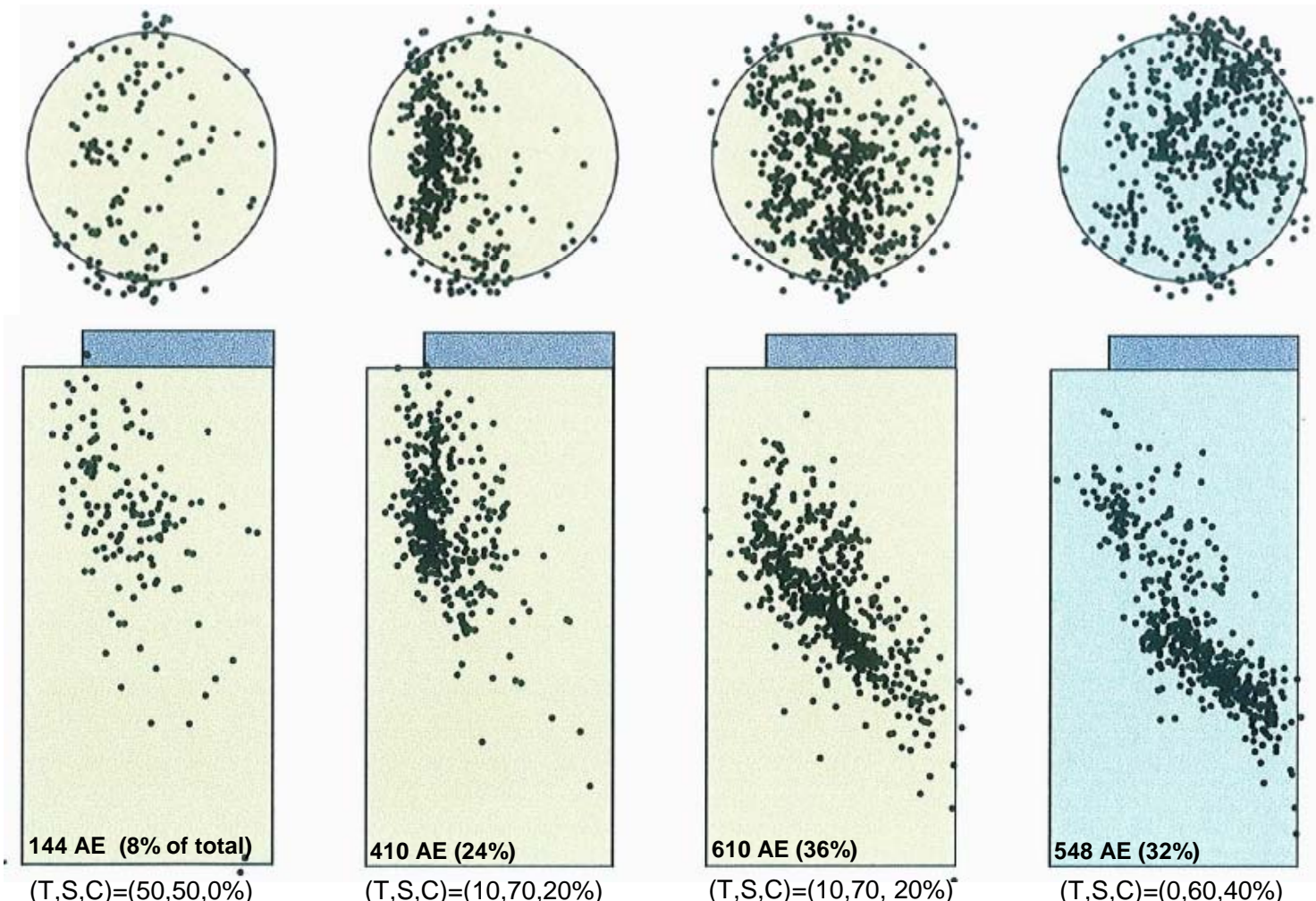

(a) Stage 1a

(b) Stage $1 \mathrm{~b}$

(c) Stage 1c

(d) Stage 2

Figure 8. Distribution of acoustic emission hypocenters detected during fracturing stage and frictional sliding stage in Aue granite tested at $10 \mathrm{MPa}$ confining pressure loaded with AE-rate control [18]. AE source statistics are presented at bottom of each figure (T: tensile, S: shear, C: pore collapse). 

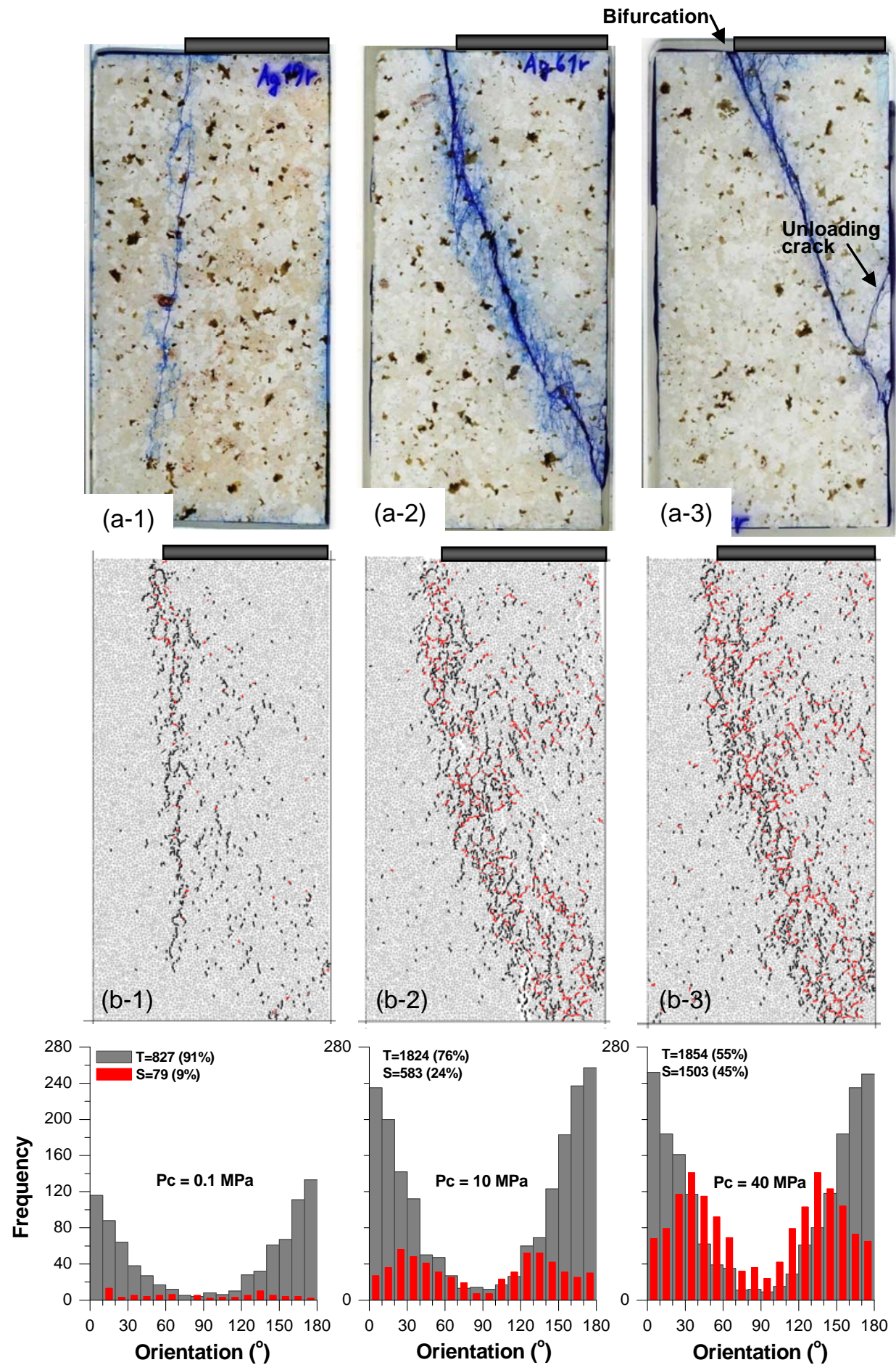

(c-1)

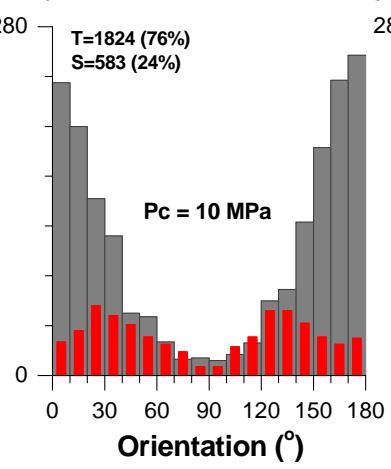

(c-2)

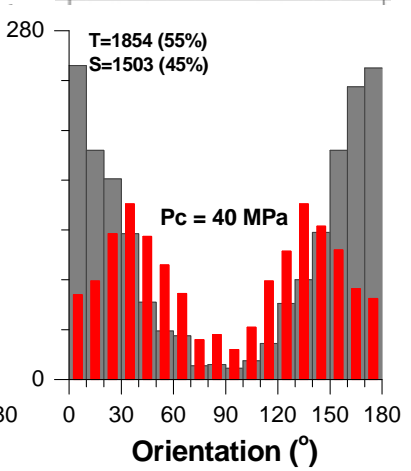

(c-3)

Figure 9. Fracture paths visible by impregnation of blue-epoxy in thin sections cut from the deformed core halves that were tested at (a-1) atmospheric, (a-2) $10 \mathrm{MPa}$ and (a-3) $40 \mathrm{MPa}$ confining pressures. Distribution of cracks in CPM tested at various confining pressures (b) (black: tensile crack, red: shear crack). Orientation distribution of crack plane normal of tensile and shear cracks (c). 


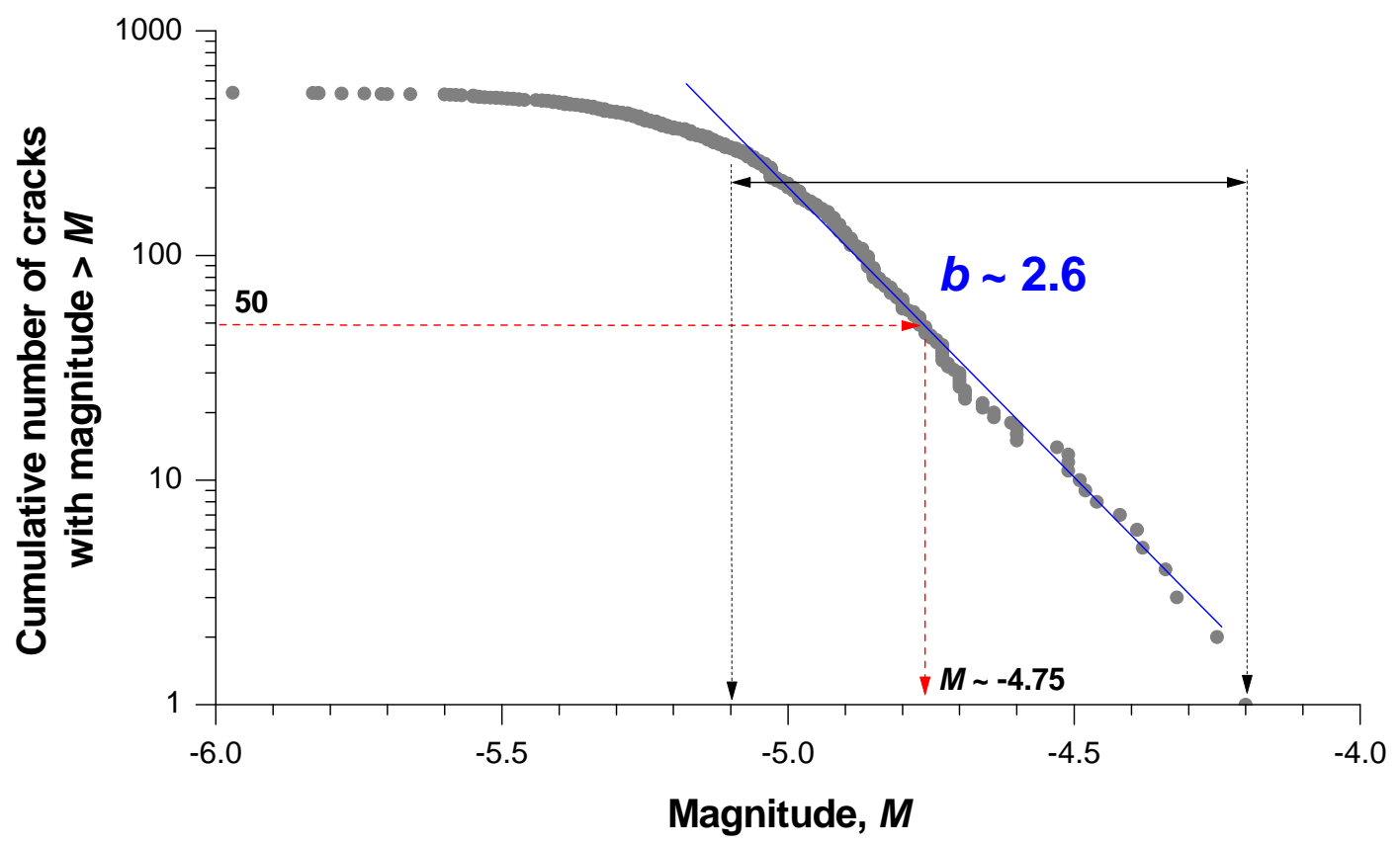

Figure 10. Moment magnitude vs. cumulative number of crack relation. $b$-value is defined as the slope of linear fit (blue line) of the plotted data (magnitude range: -5.1 to -4.2 ). Two red arrows indicate that there are about 50 cracks whose magnitude is greater than -4.75 . 


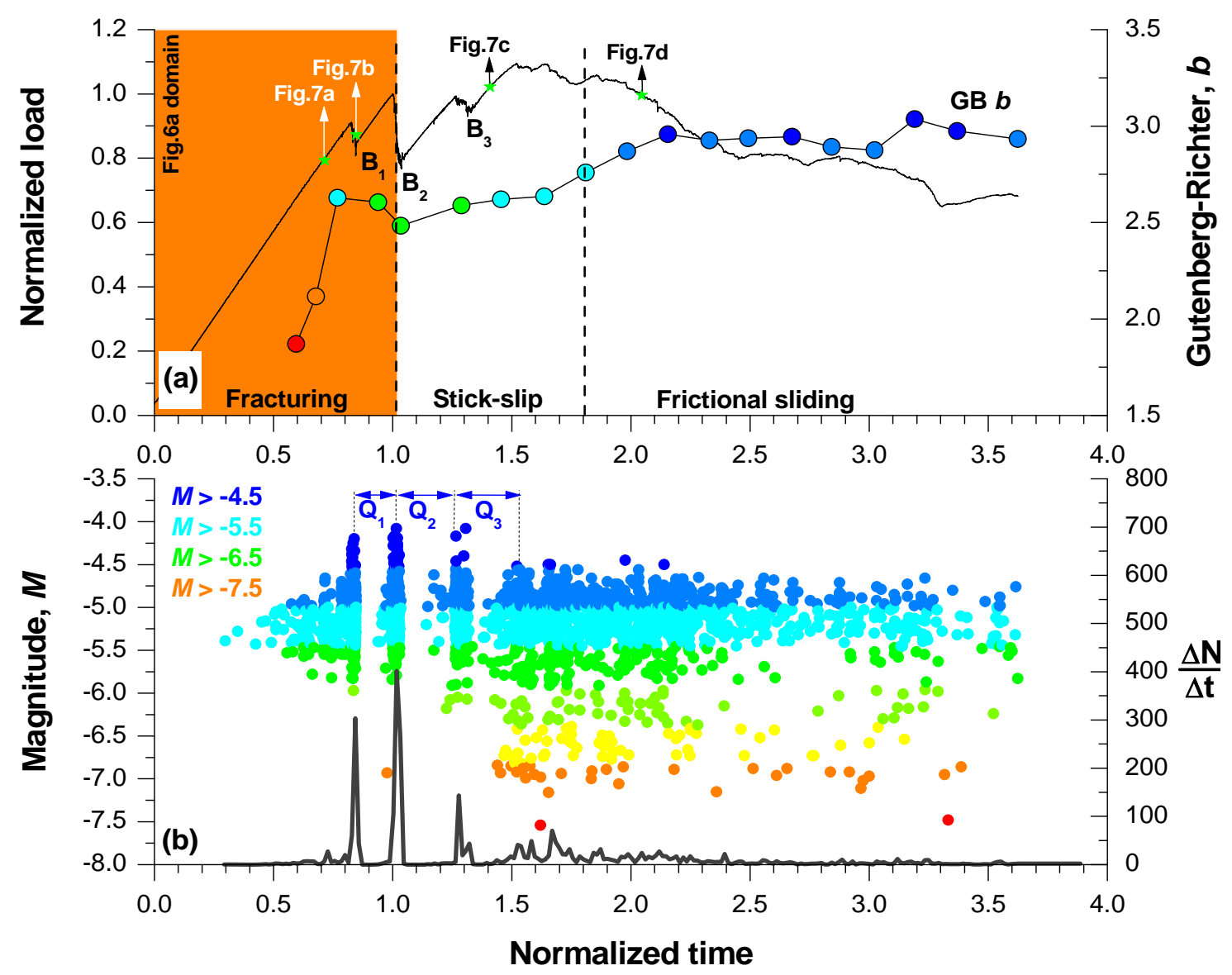

Figure 11. (a) Temporal variation of $b$-value dots with respect to load, and (b) computed moment magnitude of cracks (dots) with respect to crack rate $\Delta \mathrm{N} / \Delta \mathrm{t}$ with $\Delta \mathrm{t}=0.01$, resulting from CAT with $10 \mathrm{MPa}$ confining pressure. $\mathrm{B}_{\mathrm{i}}(\mathrm{i}=1-3)$ refer to bursts of crack rate and load drops, and $\mathrm{Q}_{i}$ to time intervals of quiescence after each burst. 


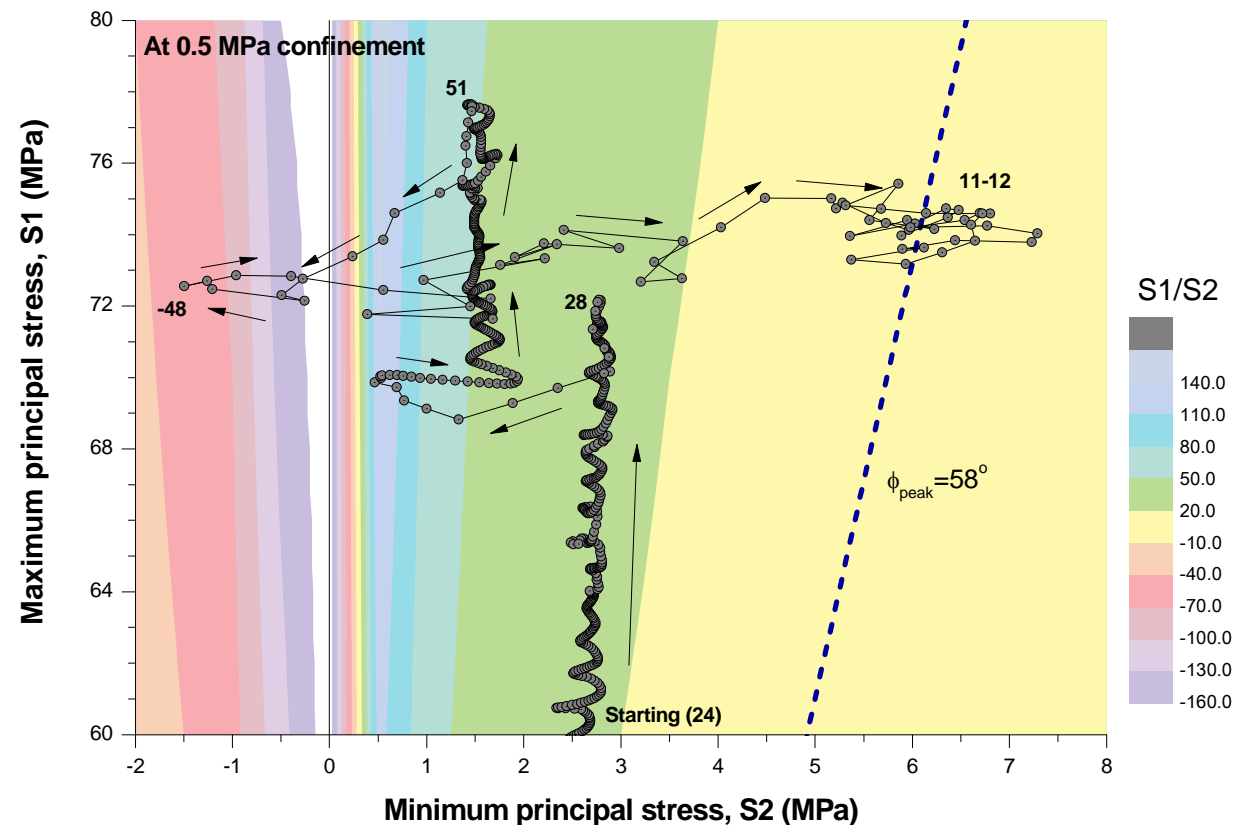

(a)

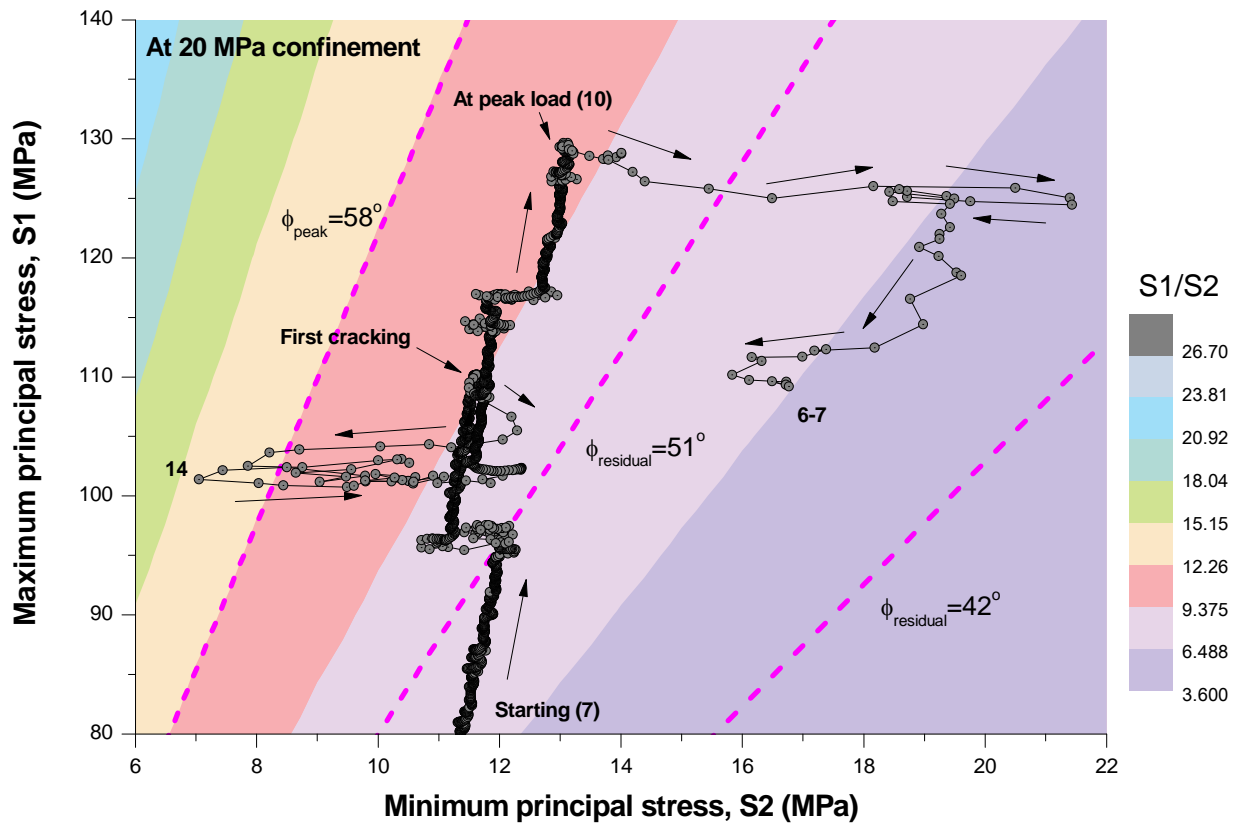

(b) 


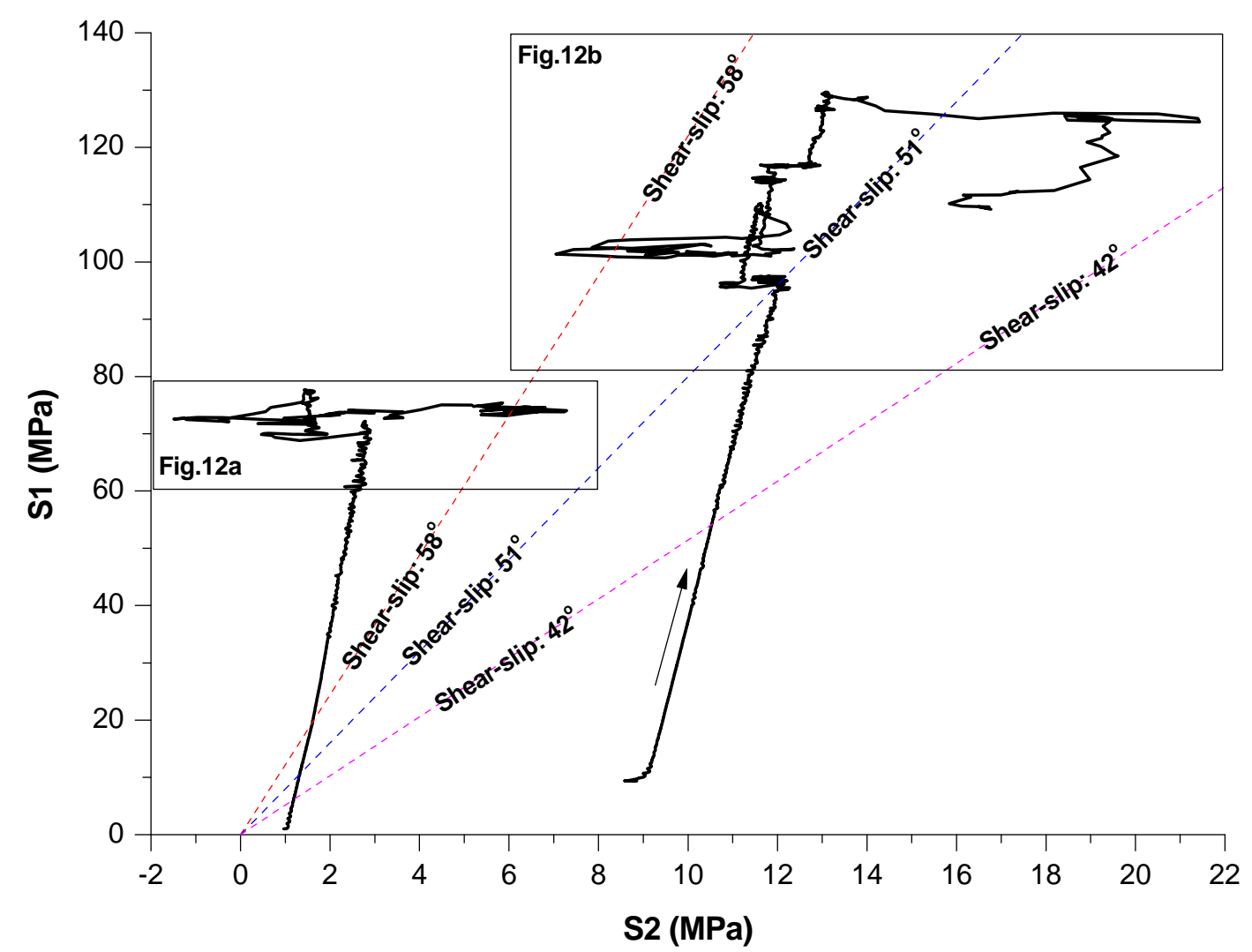

(c)

Figure 12. Principal stress paths $\left(\sigma_{1}\right.$ vs. $\left.\sigma_{2}\right)$ computed from the stress components $\left(\sigma_{\mathrm{x}}, \sigma_{\mathrm{y}}, \sigma_{\mathrm{xy}}\right)$ evolving in the monitoring circle in the CPM for the CAT scenario with (a) $0.5 \mathrm{MPa}$ and (b) 20 $\mathrm{MPa}$ confining pressures. Arrows in (a) and (b) indicate increasing time in the numerical simulation. Ratios of the principal stresses are presented by colour contours with shear-slip criteria computed from peak friction angle and residual friction angle (assuming zero cohesion, see text for equation). (c) Complete stress paths evolving in the monitoring circles in CPM tested with $0.5 \mathrm{MPa}$ and $20 \mathrm{MPa}$ confining pressures. Two rectangles indicate the $\sigma_{1}$ vs. $\sigma_{2}$ domains shown Fig.12a and 12b. 


\section{Tables}

Table 1. Macroscopic properties of Aue granite and the clumped particle model

\begin{tabular}{|c|c|c|}
\hline Property & $\begin{array}{l}\text { Aue granite } \\
\text { (Mean } \pm \text { Std.dev.) }\end{array}$ & $\begin{array}{l}\text { Clumped Particle Model } \\
(\text { Mean } \pm \text { Std.dev.) }\end{array}$ \\
\hline Uniaxial Compressive & $134 \pm 7^{1)}$ & $150 \pm 8$ \\
\hline Strength (MPa) & & \\
\hline Young's modulus (GPa) & $48 \pm 8^{1)}$ & $50 \pm 9$ \\
\hline Poisson's ratio & $0.19^{1)}$ & $0.18 \pm 0.02$ \\
\hline$\sigma_{\mathrm{ci}} / \mathrm{UCS}$ & $0.33 \pm 0.03-0.39 \pm 0.03^{2,3)}$ & $0.32 \pm 0.02$ \\
\hline$\sigma_{\mathrm{cd}} / \mathrm{UCS}$ & $0.75 \pm 0.05-0.89 \pm 0.02^{2,3)}$ & $0.87 \pm 0.03$ \\
\hline Peak friction angle $\left(^{\circ}\right)$ & 52 & 58 \\
\hline Residual friction angle $\left(^{\circ}\right)$ & - & $42-51$ \\
\hline Cohesion (MPa) & 23 & 22 \\
\hline Tensile strength (MPa) & $8 \pm 1^{4,5,6)}$ & $23 \pm 1$ \\
\hline$K_{I C}(\mathrm{MPa} \sqrt{\mathrm{m}})^{+}$ & $1.6 \pm 0.1^{5)}$ & - \\
\hline$K_{I I C}^{0}(\mathrm{MPa} \sqrt{ })^{\#}$ & $2.2-4.1^{4,5,6)}$ & - \\
\hline$K_{I I C}^{\infty}(\mathrm{MPa} \sqrt{\mathrm{m}})^{\circ}$ & $13.2^{4)}$ & \\
\hline Average size (2D area) $\left(\mathrm{mm}^{2}\right)$ & Grain: 1.43 & Clump: 2.1 \\
\hline
\end{tabular}

References: ${ }^{1)}[42],{ }^{2}[43],{ }^{3}[44],{ }^{4}[39],{ }^{5}[40],{ }^{6}[41]$

Fracture toughness test methods: ${ }^{+} \mathrm{CB}$ (Chevron Bend) method, ${ }^{\text {PTS }}$ (Punch Through Shear) test at zero confining pressure, ${ }^{\circ} \mathrm{PTS}$ test at confining pressure $>30 \mathrm{MPa}$

Table 2. Micro-parameters used for generation of bonded particle model

\begin{tabular}{lll}
\hline Micro-parameters & Values & {$[\mathrm{Units}]$} \\
\hline Particle-particle contact modulus, $E_{c}$ & 80 & {$[\mathrm{GPa}]$} \\
Contact bond normal stiffness, $k_{n}$ & 160 & {$[\mathrm{GPa} / \mathrm{m}]$} \\
Contact bond shear stiffness, $k_{s}$ & 64 & {$[\mathrm{GPa} / \mathrm{m}]$} \\
Contact friction coefficient, $\mu$ & 0.5 & {$[-]$} \\
Contact bond tensile strength (mean), $\sigma_{c, \text { mean }}$ & 100 & {$[\mathrm{MPa}]$} \\
Contact bond tensile strength (std.dev.), $\sigma_{c, \text { std.dev. }}$ & 0 & {$[\mathrm{MPa}]$} \\
Contact bond shear strength (mean), $\tau_{c, \text { mean }}$ & 200 & {$[\mathrm{MPa}]$} \\
Contact bond shear strength (std.dev.), $\tau_{c, \text { std.dev. }}$ & 0 & {$[\mathrm{MPa}]$} \\
Minimum particle radius, $r_{\min }$ & 0.25 & {$[\mathrm{~mm}]$} \\
Maximum particle radius, $r_{\max }$ & 0.42 & {$[\mathrm{~mm}]$} \\
Particle density, $\rho$ & 2600 & {$\left[\mathrm{~kg} / \mathrm{m}^{3}\right]$} \\
\hline
\end{tabular}

